Article

\title{
Integrating Sustainability and Lean: SLIM Method and Enterprise Game Proposed
}

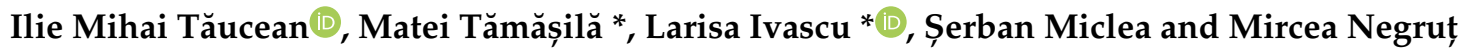 \\ Department of Management, Faculty of Management in Production and Transportation, Politehnica University \\ of Timisoara, via Victoria Square No. 2, 300006 Timisoara, Romania; ilie.taucean@upt.ro (I.M.T.); \\ serban.miclea@upt.ro (S.M.); mircea.negrut@upt.ro (M.N.) \\ * Correspondence: matei.tamasila@upt.ro (M.T.); larisa.ivascu@upt.ro (L.I.)
}

Received: 31 December 2018; Accepted: 28 March 2019; Published: 9 April 2019

check for updates

\begin{abstract}
Sustainability and leanness are organizational approach concepts for more efficient activities and increased competitiveness. This paper presents a study and an application of the concepts of sustainability and lean, with the purpose to capitalize on the benefits of the two concepts' tools when used together in an industry and education activity. A literature review was carried out to evaluate qualitatively and empirically the concepts of sustainability, lean, and enterprise games, and the possibility to integrate the first two concepts into a new tool applied into an enterprise game. An online survey was done to identify which tools are used within companies in the region, how and what training methods they used, and what the reported benefits are. The survey results were used to design a new tool integrated in a new enterprise game (SLIM) developed by the authors. The game was tested and validated in educational laboratory with students and actual employees from companies. The game follows the frame of an enterprise game, considering the simulation of enterprise classical functions. The game's purpose is to improve the activity in successive rounds. A scorecard is used to fill in and compute the key performance indicators (KPIs), and a new indicator is proposed (SLIMx). Applications of the instrument/game include: students' training in an educational laboratory; lifelong learning; professional training in companies; and professional perfection/reconversion of potential employees and the unemployed. The SLIM game was simulated in a team of 15 players over three rounds, with teachers playing the role of the supervisor. A number of possible improvements have been identified. The next step is testing it in enterprises with various fields of activity. SLIM has proven to be an effective solution to improve organizational efficiency and motivate players to gain new knowledge.
\end{abstract}

Keywords: waste management; efficiency; quality; game; sustainable development; lean production; process improvement; production flexibility

\section{Introduction}

Currently, there are a number of management approaches that contribute to increasing competitiveness and business development capacity. Some businesses are targeting environmental practices to improve process activities and improve public image. Many businesses are concerned about the tools, methods, and techniques that help streamline process resource utilization. Most are involved in corporate social responsibility activities to improve their public image. These CSR activities are complementary to processes streamlining actions. Sustainability is addressed in many companies [1-3]. The three dimensions of sustainability are addressed: social, economic, and environmental. Some organizations address cumulatively the three responsibilities, others partially. Involvement in sustainable development is not mandatory at the national or international level. Sustainability reporting is also optional [4], but many businesses report their sustainability to improve 
their impact on stakeholders. From a production efficiency perspective, lean manufacturing or lean production, often simply "lean", involves reducing the amount of waste without minimizing production capacity [5]. These goals can be achieved by using less resources to generate the same result. Operations management plays an important role in delivering positive results. The interaction between lean and sustainability is addressed in specialized literature, highlighting the benefits of the integrated use of the two concepts [2-6]. The approach of the two concepts, lean production and sustainability, within enterprises can contribute to increasing the competitiveness, capacity to develop, and make more efficient use of organizational resources (human, financial, informational, and material resources) [5-8].

In 2017, Cherrafi et al. stated that there was no study showing the relationship between sustainability and lean. Prior to 2012, most studies presented that sustainability and lean benefits were particularly limited to environmental responsibility [6-8]. After 2012, research into the integrated approach of the two concepts began to intensify [5].

The structure of the paper is as follows: a literature review of the concepts of sustainability, lean, and enterprise games, methods, and industry needs research using a questionnaire is conducted; followed by a presentation (introduction) of a new instrument; and a new enterprise game is developed by the authors (which integrates sustainability and lean concepts to address industry needs).

The objective of the paper is to introduce a new enterprise game and indicator developed by the authors following the research in the interdisciplinary domain related to two concepts: sustainability and lean. These two concepts are considered here together, and integrated with similarities and complementarities which should lead to improvement in companies' competitiveness.

\section{Introducing Concepts of Lean and Sustainability with Enterprise Games}

\subsection{The Implication of Sustainability}

From the perspective of enterprises, their actions on increasing competitiveness and making production more efficient have become necessary and mandatory. The urgency to get involved in environmental protection, sustaining society, and improving economic performance (the triple baseline-TBL) was mainly due to the fact that companies began to feel more pressure from stakeholders than ever [8-11]. Long-term organizational survival conditions have changed so that social and environmental performance aspects in addition to financial excellence are included [12]. They, therefore, sought to respect the widespread recognition of voluntary and imposed regulations, actions and standards developed by national and global authorities such as: International Standards Organization (ISO): ISO 14000 series—Environmental Protection Oriented, ISO 9000 series—Quality Oriented, ISO 45000 series-Health and Safety Oriented, ISO 27000 series-Information Security Oriented, Occupational Safety and Health Administration (OSHA); Occupational Safety and Health Administration (OSHA): Occupational Safety and Health Act of 1970-Safety and Health Oriented; British Standards Institution (BSI): OHSAS 18000 series-Health and Safety Oriented; US Environment Protection Agency (EPA); Lean and Environment Toolkit-Environment Protection Oriented; Lean, Energy and Climate Toolkit-Environment Protection and Resource Preservation Oriented; European Union (EU) Standards: Eco-Management and Audit Scheme (EMAS)—Environment Protection Oriented, Health and Safety at Work Act, 7 Waste; Life Cycle Sustainability Assessment-LCSA; Resource Efficient and Cleaner Production-RECP and other [3-11].

Sustainable development targets 17 principles and 169 targets. The 17 Sustainable Development Goals (17 SDGs) are accompanied by 169 specific targets and are part of the strategic document called the "2030 Agenda for Sustainable Development". The implications of the 17 SDGs are presented in Table 1. 
Table 1. Short description of the 17 Sustainable Development Goals.

\begin{tabular}{cl}
\hline Goal & Short Description \\
\hline SDG 1 & Eradicate poverty in all its forms \\
SDG 2 & Food safety and sustainable agriculture \\
SDG 3 & Healthy life at all ages \\
SDG 4 & Lifelong learning \\
SDG 5 & Equality between women and men \\
SDG 6 & Sustainable water management and sanitation for all \\
SDG 7 & Affordable prices and sustainable resources \\
SDG 8 & Promoting economic growth, productive and decent work \\
SDG 9 & Promoting industrialization and stimulating innovation \\
SDG 10 & Reducing inequalities between countries \\
SDG 11 & Developing secure living environments \\
SDG 12 & Sustainable consumption and efficient production \\
SDG 13 & Urgent action to combat climate change \\
SDG 14 & Sustainable use of marine resources \\
SDG 15 & Restoration of terrestrial ecosystems \\
SDG 16 & Responsibility of society and equity of institutional levels \\
SDG 17 & Partnerships for the goals \\
\hline
\end{tabular}

The development of this strategic document was based on a series of steps that have taken place since 1951 (see Figure 1) [3-7]. The first actions aimed at sustainable development took place in 1951 at the International Union for Nature Conservation. The Rome Club has set up environmental actions. Our Common Future, also known as the Brundtland Report, has laid the foundations for sustainable development, being an important document for this endeavor. In 2015, on the basis of Agenda 2030 sustainable development goals are set out $[13,14]$.

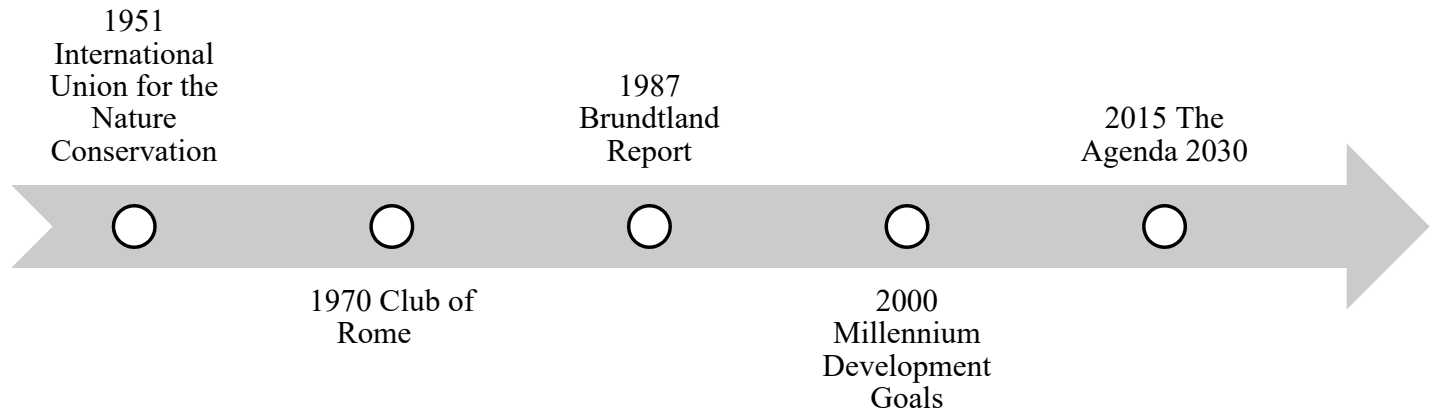

Figure 1. The evolution of Agenda 2030.

On global markets, meeting agenda goals will generate the following [5-11]: Strengthening new markets for sustainable products and services; globalization of service and product markets; reengineering the organizational processes; reducing the amount of waste generated; pressures on the business environment to make more efficient use of resources; passing economic agents to use energy from renewable energy sources; increasing the living standards of companies, new opportunities for communities, consumers and employees offered by sustainable products and services; new projects for the development of infrastructure for energy production, water distribution, transportation and rehabilitation of the quality of life of all.

Sustainability at enterprise level addresses a number of improvements [5-13] that can be structured in the form of 12 principles [14]. The proposed principles cover the objectives of Agenda 2030, as outlined in Table 2. 
Table 2. The 12 principles of sustainability proposed, the implications and objectives of Agenda 2030 covered by them.

\begin{tabular}{|c|c|c|c|}
\hline No. & Principle & Implication & Goal \\
\hline S1 & Reducing resources & $\begin{array}{l}\text { Reducing process losses contributes to improving } \\
\text { financial results. }\end{array}$ & SDG9, SDG12 \\
\hline $\mathrm{S} 2$ & Time efficiency & $\begin{array}{l}\text { Improving the time of the enterprise processes } \\
\text { contributes to increased production capacity and } \\
\text { reduced costs. }\end{array}$ & SDG9, SDG12 \\
\hline S3 & $\begin{array}{l}\text { Reducing waiting } \\
\text { time }\end{array}$ & $\begin{array}{l}\text { The company has to reduce its waiting time to } \\
\text { improve its production capacity. }\end{array}$ & SDG9, SDG12 \\
\hline S4 & $\begin{array}{l}\text { Monitoring fixed } \\
\text { costs }\end{array}$ & $\begin{array}{l}\text { Reducing energy consumption, mainly to } \\
\text { improve financial results and reduce } \\
\text { environmental impact. }\end{array}$ & SDG12, SDG17 \\
\hline S5 & $\begin{array}{l}\text { Stakeholder } \\
\text { engagement in } \\
\text { strategic decisions }\end{array}$ & $\begin{array}{l}\text { Strategic decisions, in particular, need to be } \\
\text { agreed by stakeholders, thereby increasing the } \\
\text { attractiveness and efficiency (by involving } \\
\text { stakeholders from within) }\end{array}$ & SDG6, SDG8, SDG17 \\
\hline S6 & $\begin{array}{c}\text { Supporting } \\
\text { community activities }\end{array}$ & $\begin{array}{l}\text { The enterprise must meet the needs of the } \\
\text { communities and thus the level of } \\
\text { competitiveness can be improved. }\end{array}$ & SDG2, SDG3, SDG16 \\
\hline S7 & $\begin{array}{l}\text { Training human } \\
\text { resources }\end{array}$ & $\begin{array}{l}\text { Through continuous training of human resources, } \\
\text { the company's performance level is improved. }\end{array}$ & SDG4, SDG5 \\
\hline S8 & $\begin{array}{c}\text { Corporate Social } \\
\text { Responsibility (CSR) }\end{array}$ & $\begin{array}{l}\text { The company's involvement in CSR activities } \\
\text { increases the company's attractiveness and } \\
\text { improves some activities. }\end{array}$ & SDG 1, SDG10 \\
\hline S9 & $\begin{array}{l}\text { Increasing recycling } \\
\text { capacity }\end{array}$ & $\begin{array}{l}\text { The enterprise must have the capacity to recycle } \\
\text { the waste generated in order to reduce the } \\
\text { impact on the environment. }\end{array}$ & SDG14, SDG15 \\
\hline S10 & $\begin{array}{l}\text { Increasing the } \\
\text { capacity of the reuse, } \\
\text { remanufacturing, } \\
\text { reconditioning }\end{array}$ & $\begin{array}{l}\text { Process-generated waste must be input for other } \\
\text { processes. Thus the amount of waste generated } \\
\text { could decrease considerably. }\end{array}$ & SDG7, SDG12 \\
\hline S11 & $\begin{array}{l}\text { Reducing energy } \\
\text { consumption }\end{array}$ & $\begin{array}{l}\text { Improving enterprise processes so that energy } \\
\text { consumption is reduced. Increasing the } \\
\text { enterprise's capacity to generate energy. }\end{array}$ & SDG9, SDG13 \\
\hline S12 & $\begin{array}{l}\text { Greenhouse gas } \\
\text { reduction }\end{array}$ & Reducing pollution to the environment. & SDG11, SDG13 \\
\hline
\end{tabular}

\subsection{The Concept of Lean}

Operations management plays an important role in delivering positive results.

Research is beginning to correlate lean operations with sustainability, breaking down the "lean is green" approach [12-16]. One of the lean operation goals is to use fewer resources to generate the same result. This is obviously environmentally friendly: since less use of materials in production leads to reduced environmental impact and also quality improvements reduce reuse, reconditioning, or remanufacturing, waste is reduced and pollution costs diminished, so the environmental benefits are obvious [7]. Reducing materials used in operations leads to cost savings, thus addressing the economic sustainability dimension. Efficiency of operations contributes to reducing energy, water and other costs. Therefore, lean principles match the main sustainability objectives and reach the main objectives of the sustainability agenda. This is because the lean concept can reduce the amount of waste eliminated, improve the whole process, and reduce the negative impact of processes on the environment, streamline resource consumption, improve product quality, and more [5-12]. It is said that lean produces a very favorable operational and cultural character for minimizing waste and reducing greenhouse gases. By reducing greenhouse gas emissions and minimizing waste, the lean 
concept promotes sustainability in business processes [12-14]. Among the most used tools lean for sustainability purposes were identified to be Value Stream Mapping (VSM), 5S, Kaizen, Just-In-Time (JIT), Cellular Manufacturing, Single Minute Exchange of Dies (SMED), Standardized Work, and Total Preventive Maintenance (TPM), Plan-Do-Check-Act (PDCA), and Problem Solving. Other lean tools, methods, and techniques that have a potential contribution to sustainable development are: Sort-Set In order-Shine-Standardize-Sustain (5S), Six Sigma, Jidoka, Gemba Walk, Kaikaku, Shop Floor Management (SFM), Bottleneck Analysis, and others [5-8,15]. Lean manufacturing leads to a series of improvements [7-12,14-16], in the short- and long-term, at the level of the enterprises, as follows:

- Improving quality—a considerable part of lean environment activities is directed to improving the quality of operations.

- Improved visual management-an improved visual scan helps to increase time for operations.

- Increased efficiency-standardized activities contribute to increasing resource efficiency.

- Manpower reductions-if emphasis is placed on standardized work and increased efficiency, the ability to perform operations with fewer people becomes a very real possibility.

- Easier to manage-standardization activities and increased operations efficiency contribute to the development of an easy-to-manage environment.

- Problem elimination-lean principles force the investigation of the identified problem until it is eliminated.

- Redundant space-streamlining raw material consumption, waste reduction and standardized work contributes to reducing the space used (stocks no longer occupy a lot of space vertically and horizontally).

- Safer work environment-unnecessary things taken from current operations contribute to conducting an organized job (example $5 \mathrm{~S}$ technique).

- Improved employee morale-if the lean concept implementation is accepted by employees, there will be a decrease in the stress level and employee morale will improve.

\subsection{The Relation between Lean and Sustainability Indices}

Between lean and sustainability there is a relationship and interaction that contributes to increasing competitiveness and making production more efficient [8-16]. In vision [7] it is stated that lean represents the holistic vision of sustainability and streamlines processes in terms of costs, time, waste, and quality. This approach covers part of the sustainability objectives (SDG9, SDG12, SDG13) taking into account the quality of the environment, social equity, and the economy. In another approach [9], it takes into account the principles of sustainability, focusing on environmental protection, re-use of waste, and reducing greenhouse gas emissions. Cherrafi et al. asserts that sustainable development is indispensable in the lean approach, as reducing energy consumption, reducing environmental pollution, and streamlining material consumption cover the principles of sustainability [8]. The implications of sustainability are found in the operational part of lean production. Studies conducted to research the relationship between leanness and sustainability [1-14] show that the application of lean concepts and sustainability shows a number of similarities and complementarities. By applying these two concepts, businesses could achieve increased performance [14-16]. Following the evaluation of the specialized literature and the implications of the lean concept, 12 principles are proposed, presented in Table 3. 
Table 3. The 12 principles of sustainability (S1-S12) and the 12 principles of lean (L1-L12).

\begin{tabular}{|c|c|c|c|}
\hline No. & Sustainability's Principle & No. & Lean's Principle \\
\hline S1 & Reducing resources & L1 & $\begin{array}{l}\text { Reducing/Eliminating activities that do } \\
\text { not add value }\end{array}$ \\
\hline S2 & Time efficiency & $\mathrm{L} 2$ & Reducing uncertainty \\
\hline S3 & Reducing waiting time & L3 & Focus on customer requirements \\
\hline $\mathrm{S} 4$ & Monitoring fixed costs & $\mathrm{L} 4$ & Reduce cycle time \\
\hline S5 & $\begin{array}{l}\text { Stakeholder engagement in strategic } \\
\text { decisions }\end{array}$ & L5 & Simplifying the process \\
\hline S6 & Supporting community activities & L6 & Increase production flexibility \\
\hline S7 & Training human resources & L7 & Increase process transparency \\
\hline S8 & Corporate Social Responsibility (CSR) & L8 & Controlling the entire process \\
\hline S9 & Increasing recycling capacity & L9 & Improving the process continuously \\
\hline S10 & $\begin{array}{l}\text { Increasing the capacity of the reuse, } \\
\text { remanufacturing, reconditioning }\end{array}$ & L10 & $\begin{array}{l}\text { Gathering information about } \\
\text { competitors }\end{array}$ \\
\hline S11 & Reducing energy consumption & L11 & Reduction of raw materials \\
\hline S12 & Greenhouse gas reduction & L12 & Efficient allocation of human resources \\
\hline
\end{tabular}

Following the identification of the 12 principles of sustainability and 12 principles of lean, this research identifies a number of similarities and complementarities in order to increase the interest of enterprises in implementing the tools targeted by the two concepts. In the first stage, Table 4 presents a matrix of the interaction of the principles of sustainability with those of lean. This matrix is presented in Table 4. It can be seen that S1 principle of sustainability presents the same areas of interest with L1, L2, L4, L7, L9, L11, and L12 principles of lean. The sustainability principle S4 presents areas of common interest with lean principles L9 and L11. The S12 principle interacts with lean manufacturing L1, L4, L5, L8, L9, and L11.

Table 4. The interaction matrix between lean operation and sustainability criteria in management process.

\begin{tabular}{|c|c|c|c|c|c|c|c|c|c|c|c|c|}
\hline \multirow{2}{*}{ Sustainability's Principle } & \multicolumn{12}{|c|}{ Lean's Principle } \\
\hline & L1 & L2 & L3 & L4 & L5 & L6 & L7 & L8 & L9 & L10 & L11 & L12 \\
\hline S1 & $x$ & $x$ & & $x$ & & & $x$ & & $x$ & & $x$ & $x$ \\
\hline $\mathrm{S} 2$ & & $x$ & $x$ & & & & $x$ & & & & & \\
\hline S3 & & & $x$ & & $x$ & & & & & & & \\
\hline S4 & & & & & & & & & $x$ & & $x$ & \\
\hline S5 & & & & & & & & & & $x$ & & $x$ \\
\hline S6 & & & $x$ & & & & & & & & & $x$ \\
\hline S7 & & & & & & & & $x$ & & & & $x$ \\
\hline S8 & & & & & & & & & & & & $x$ \\
\hline S9 & & & & & $x$ & $x$ & & & $x$ & & & \\
\hline S10 & $x$ & & & & & $\mathrm{x}$ & & $x$ & & & & \\
\hline S11 & & $x$ & & & $x$ & $x$ & $x$ & $x$ & $x$ & & & \\
\hline S12 & $x$ & & & $x$ & $x$ & & & $x$ & $x$ & & $x$ & \\
\hline
\end{tabular}

From the perspective of similarities and complementarities that can be identified between the 24 principles, the proposal in Table 5 is presented. It can be seen that the principle S3 and the principles L3-L5 refer to the waiting time. Lean aims to get the wanted product in the shortest time, and the sustainability is reducing the allocation of resources to achieve goals for a long time. The S7 principle interacts with the L8-L12. The action of these concepts is similar in relation to human resources, and as a complementarity, lean pursues the efficiency of resources, and sustainability supports employee training (employee continuous training). 
Table 5. Addressing the similarities and complementarities of lean and sustainability principles.

\begin{tabular}{|c|c|c|c|}
\hline Sustainability's Principle & Lean's Principle & $\begin{array}{l}\text { The Similarities } \\
\text { of Principles }\end{array}$ & Complementarity of Principles \\
\hline S1 & $\begin{array}{l}\text { L1, L2, L4, L7, L9, } \\
\text { L11, L12 }\end{array}$ & Reducing resources & $\begin{array}{l}\text { Lean respond punctually on different } \\
\text { resources }\end{array}$ \\
\hline S2 & L2, L3, L7 & Time efficiency & $\begin{array}{l}\text { Lean streamlines operations, and } \\
\text { Sustainability plans }\end{array}$ \\
\hline S3 & L3, L5 & Waiting time & $\begin{array}{l}\text { Lean gets the product in a short time, } \\
\text { and Sustainability reduces the } \\
\text { time allotted }\end{array}$ \\
\hline S4 & L9, L11 & Process costs & $\begin{array}{l}\text { Lean controls operations for efficiency, } \\
\text { and Sustainability reduces fixed costs }\end{array}$ \\
\hline S5 & L10, L12 & $\begin{array}{l}\text { Interest towards } \\
\text { stakeholders }\end{array}$ & $\begin{array}{l}\text { Lean evaluates competitors' operations } \\
\text { and allocates efficient human resources, } \\
\text { and Sustainability involves stakeholders } \\
\text { in decision-making }\end{array}$ \\
\hline S6 & L3, L12 & Activities for people & $\begin{array}{l}\text { Lean involves employees, and } \\
\text { sustainability supports the } \\
\text { organization's involvement in society }\end{array}$ \\
\hline S7 & L8, L12 & Human resource & $\begin{array}{l}\text { Lean pursues resource efficiency, } \\
\text { Sustainability supports } \\
\text { employee training }\end{array}$ \\
\hline S8 & L12 & CSR & $\begin{array}{l}\text { Lean sustains organizational efficiency, } \\
\text { and Sustainability activities for society }\end{array}$ \\
\hline S9 & L5, L6, L9 & Recycling & $\begin{array}{l}\text { Lean aims to reduce losses, } \\
\text { Sustainability aims to increase } \\
\text { recycling rate }\end{array}$ \\
\hline S10 & L1, L6, L8 & Reverse logistics & $\begin{array}{l}\text { Lean supports loss reduction, and } \\
\text { Sustainability supports reverse logistics } \\
\text { (returning waste to production as } \\
\text { raw materials) }\end{array}$ \\
\hline S11 & L2, L5, L6, L7, L8, L9 & Energetic efficiency & $\begin{array}{l}\text { Lean reduces loss, sustainability sustains } \\
\text { the production of green energy }\end{array}$ \\
\hline S12 & L1, L4, L5, L8, L9, L11 & Pollution Reduction & $\begin{array}{l}\text { Lean reduces waste, and Sustainability is } \\
\text { aimed at reducing greenhouse gases }\end{array}$ \\
\hline
\end{tabular}

Based on these interactions, similarities and complementarities, at the level of specialized literature research, the next step is realized in the present research. The following are the results obtained from a market research aimed at identifying the needs and wants of training and implementation in the economic environment.

\subsection{Enterprise Games}

This paper proposes an inter-disciplinary research in the domain of "engineering and management", starting from 2005, and developed from 1990 with different names and directions (industrial engineering, production system engineering) and 1992 (engineering economy). This needs modern educational systems to improve the efficiency and quality of graduates for a fast integration in the labor market. The main advantages of the new game proposed will not only help to reduce and eliminate existing bottlenecks in university education. It will support the educational process through modern tools; the efficient use of educational resources; superior learning process facilitation; phenomena simulation that otherwise will be impossible or highly costly; and creativity and competition stimulation of individual and teamwork.

The Bologna Declaration of 1999 has had a very high impact on educational programs. The aim was to create a European Higher Education Area (EU 2000), and the Lisbon Strategy of 2000 (EU 2000) to create a European research and Innovation Area. The Lisbon Summit stated that, in order to make Europe the most competitive knowledge-based society in the world by the 2010, we need more and 
better trained researchers (EU 2000). By the end of 2010, most of the goals of the Lisbon Strategy were not met. Official appraisal of the Lisbon Strategy took place in 2010 at a European Summit, where the new "Europe 2020" strategy was also launched. It aims at "smart, sustainable, inclusive growth" with greater coordination of national and European policy (EU 2010). The strategy promotes modernizing education and training. Quantitative targets are proposed, including increasing the employment rate to at least $75 \%$ from the current $69 \%$ and boosting spending on research and development to $3 \%$ of gross domestic product-it is currently only $2 \%$ of GDP, significantly less than in the US and Japan [15-17].

One of the most efficient ways to learn by experience in management and engineering (in initial training, in universities and business schools, as well in continuous training in enterprises where employee work) is the use of enterprise games. Enterprise games where developed from the war game model of training, by simulating conflict situations and by applying efficient war strategies. The first one was realized by the American Management Association in 1950 [18,19]. Later, many universities on business administration introduced games in university curricula, and some companies (IBM, General Electric) elaborate their own games which were used in training managers or to support strategic decisions (especially investments decisions) [20]. With games, an organization can shift from an outmoded top-down hierarchy to an agile network structure that promotes coordination over control. Industrial Age business structures from the 20th century no longer work. It is necessary to design real-time business collaboration systems, using massively multiplayer game concepts, making in-house systems more agile [18].

Simulation of production processes is a less common (usually simulation is about information flows) and is usually harder than other enterprise departments because of the differences in each type of production system (even in the same domain, with the same products) and the multitude of activities category and different procedures/algorithms. Benchmarking analysis will lead to improved academic organization structure, of educational options for students (new study plans for license and master levels, new directions of research at the doctoral level, improvement of existing ones and correlation of them), will ensure a better students and graduates training to cope with labor market challenges, and will lead to better trainer quality by using new/innovating training tools [15-21].

In Romania, the educational system was pushed towards using games (simulation games, enterprise games, management/business games, practice enterprise), integrated in teaching activities, by necessity from the 1990s [21-23]. The necessity of students' training in the same conditions as in future workplaces, with minimum costs, was implemented in universities and high school education through practice enterprise tools, in which we have identical activities as in real enterprises, using the same procedures and benefits from the same structure [24]. There is a European network where practice firms can affiliate, entitled the European Practice Enterprises Network (EUROPEN), founded in 1997. The practice firms in the domain of Engineering and Management has existed in Romania from 2001.

Additionally, many games were used and are used today in universities for teaching and learning, developed outside Romania (e.g., INNOV8 [25]) or in Romania (e.g., TOPSIM, CEFE [26], CORAV [27], "Simulation enterprise" [28], PRELEM XXI [29], and "Decision in cascade" [30]). Considering all of these, the authors can consider that educational system of Romania is adequate enough to ease the implementation of games in the teaching activities, such as the one proposed in the paper. The new game was developed by the authors within a project framework especially to be used in an educational laboratory for student teaching. The approval of this project to be implemented in the university also explains the policy-makers' implications of the new methods and instruments to be used in university education.

\section{Methods}

For each part of the paper we use specific methods.

In the first part we conducted a literature review to evaluate qualitatively and empirically the concepts of sustainability, lean, and enterprise games, and the possibility to integrate the first two 
concepts into a new instrument applied into a new enterprise game. The authors have identified a number of improvements that develop a sustainable development into an enterprise. The number of improvements we have structured in the form of 12 principles (S1-S12, Table 2). Then, the authors identified a number of improvements made by the lean concept. We have structured the number of improvements in the form of 12 principles (L1-L12, Table 3). Following the identification of the 12 principles of sustainability and 12 principles of lean, the authors identify a number of similarities and complementarities in order to increase the interest of enterprises in implementing the tools targeted by the two concepts (Table 4). The similarities and complementarities are included in the market research (online survey), and then in the new algorithm of the new game developed by the authors.

Using an online survey, we collected data regarding the needs to use "lean" and "sustainability" tools within companies in our region. The survey contained a total of 14 questions, out of which 10 structured question with predetermined response options (dichotomic answers, multiple answers and a five-point Likert scale), while the rest of them were structured for open response options. The purpose of the survey was to identify which tools of "lean" and "sustainability" concepts are used within the companies, how and what training tools they used, which are the reported benefits of using the tools, and if the companies create an annual sustainability report.

Addressing the sustainability and lean concepts is very important for organizational competitiveness. A number of important directions have been identified through this online survey. Based on the "Interaction matrix between lean operation and sustainability criteria in the management process (Table 4)", and the results of the online market research, the authors developed a new game. Our approach, based on an enterprise game, proposes a number of improvements to the enterprise's issues. In Figure 2 are presented the enterprise architecture (EA) issues. There are several EAs, as follows: EA developed by Sparx Systems in Australia, BIZZdesign developed by IBM in Netherland, PowerDesigner developed by Novalys in France, ArchiMate developed by team from the Telematica Instituut in cooperation with Dutch partners from government, industry and academia in the Netherlands. We used ArchiMate ${ }^{\circledR}$ to build the enterprise architecture. This is one of the open standards hosted by The Open Group ${ }^{\circledR}$ and is fully aligned with TOGAF ${ }^{\circledR}$. Enterprise issues solved by our enterprise game are: enterprise management, production efficiency, warehouse efficiency, quality assessment, customer relationship management (CRM), and environmental impact.

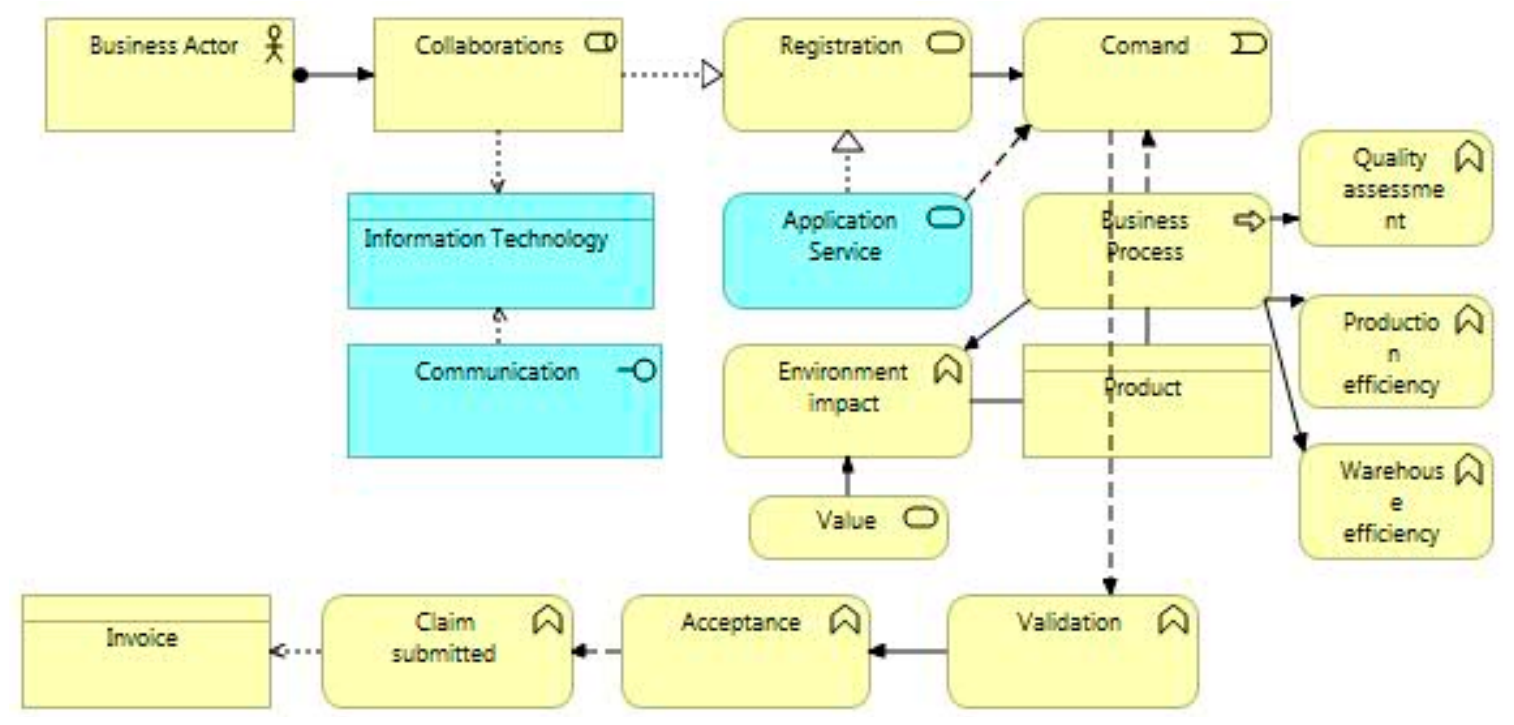

Figure 2. Enterprise architecture issues.

Using on the survey results, we design and tested an enterprise game. The game follows the framework of an enterprise game, considering the simulation of an enterprise classical functions and departments, jobs implemented in order that the enterprise activity is simulated in rounds (like work 
days or shifts). The purpose of the game is to improve the activity results in successive rounds, using sustainability and lean tools. A scorecard is used to compute the key performance indicators (KPIs), and the main indicator used here is an aggregate one from sustainability and lean indicators.

\section{Results of the "Lean" and "Sustainability" Surveys}

A total of 65 valid responses $(\mathrm{N})$ were obtained from companies' employees situated in the western region of Romania and represent the database for our descriptive statistics and main results. We have conducted statistical analysis on our survey result by computing in SPSS the standard deviation (Std. Dev. or SD) to determine if our responses are concentrated around the mean and standard error (Std. Err or SE) to indicate the reliability of the mean.

From Figure 3 we can observe that most respondents are from the administrative or support department $(43.08 \%)$, followed by the technical department (35.38\%). The answers have been obtained from the following areas: production areas $(21.54 \%)$, thus recoding smaller percentages for production managers $(16.92 \%)$, and respective production operators $(4.62 \%)$.

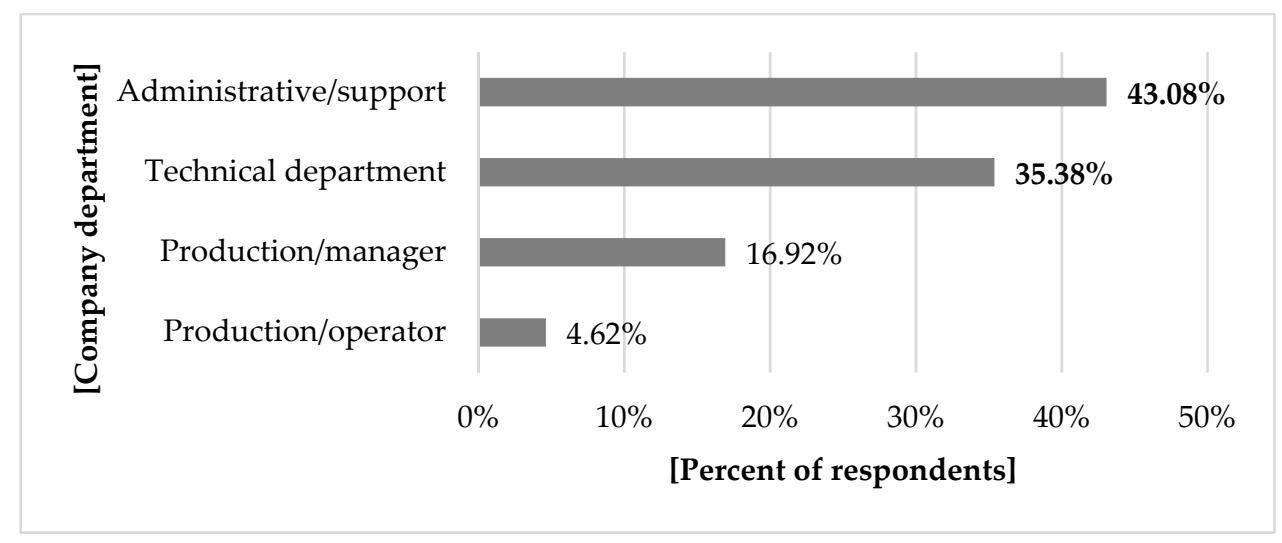

Figure 3. The percentage of respondents based on company department.

After coding our responses with " 1 " for production/operator, " 2 " for production/manager, " 3 " for administrative/support, and " 4 " for technical department, in Table 6 we can observe the distribution of respondents based on company department. Looking at the mean (3.09) and SD (0.843) values we can observe that most of the respondents are from the administrative/support and technical department.

Table 6. Descriptive statistic for the number of respondents based on company department.

\begin{tabular}{ccccccc}
\hline & $\mathbf{N}$ & Min. & Max. & \multicolumn{2}{c}{ Mean } & \multicolumn{2}{c}{ Std. Dev. } \\
\cline { 2 - 7 } & Statistic & Statistic & Statistic & Statistic & Std. Err. & Statistic \\
\hline Company department & 65 & 1 & 4 & 3.09 & 0.105 & 0.843 \\
\hline
\end{tabular}

Figure 4 presents the percentage of respondents based on the companies' business sector, from which we can observe that half of the respondents are from companies operating in the automotive business sector $(50.70 \%)$. The high percentage was to be expected due to the large number of companies situated in the western region of Romania operating in this specific business sector. 


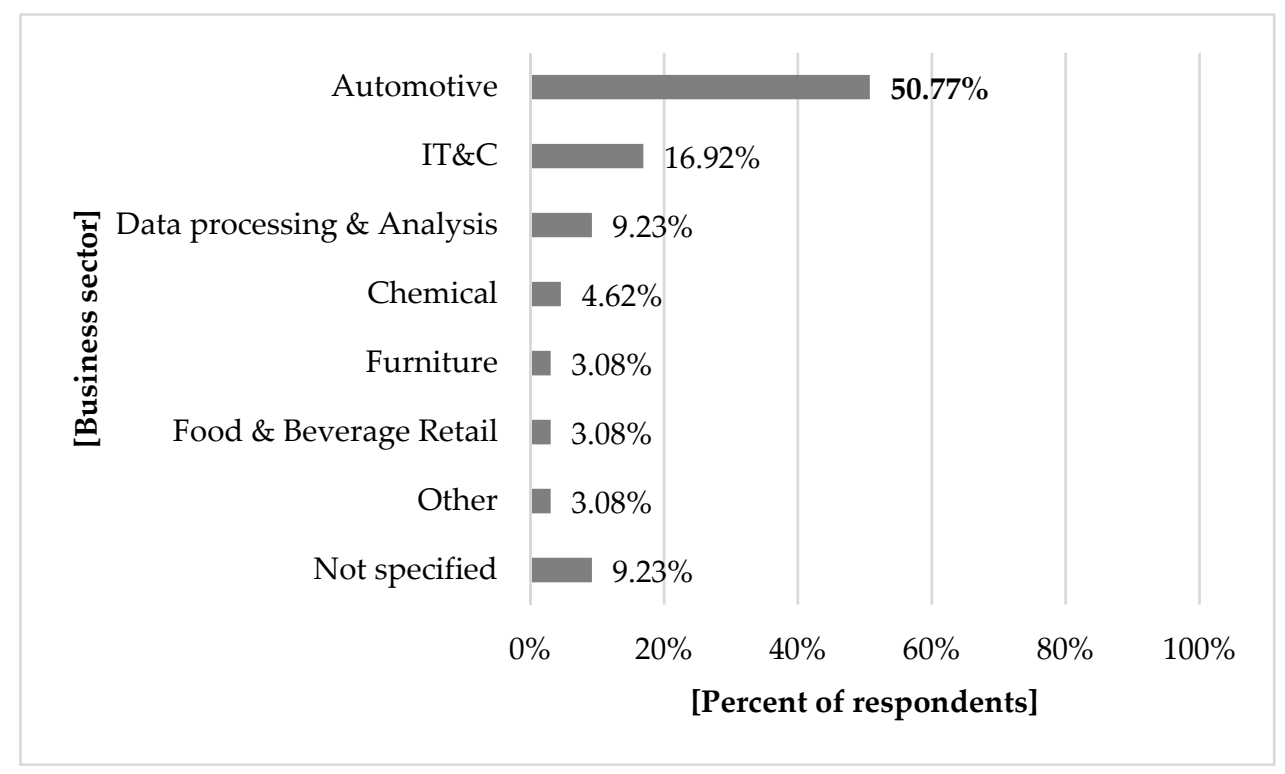

Figure 4. The percentage of respondents based on company industry.

Table 7 show the distribution of respondents based on company industry. We coded with values from 1 to 8 the industries that can be found in the Western Region of Romania: automotive, IT and C; data processing and analysis; chemical, food, and beverage retail; furniture; and included possible responses for "other industries", respectively "not specified". The high value of the SD (2.317) indicates a wide distribution of responses, meaning that we obtained several responses for each industry, while the mean (2.60) and SE (0.287) values, show that the responses are concentrated around the first two industries: automotive and IT and C.

Table 7. Descriptive statistic for the number of respondents based on company industry.

\begin{tabular}{ccccccc}
\hline & $\mathbf{N}$ & Min. & Max. & \multicolumn{2}{c}{ Mean } & Std. Dev. \\
\cline { 2 - 7 } & Statistic & Statistic & Statistic & Statistic & Std. Err. & Statistic \\
\hline Company industry & 65 & 1 & 8 & 2.60 & 0.287 & 2.317 \\
\hline
\end{tabular}

Figure 5 describes the percentage of respondents' knowledge of the "lean" and "sustainability" concept, showing us that individually asking about the concepts $73.85 \%$ have knowledge about the "lean" concept, while $89.23 \%$ about the "sustainability" concept. Additionally, $63.08 \%$ of respondents have knowledge regarding both concepts.

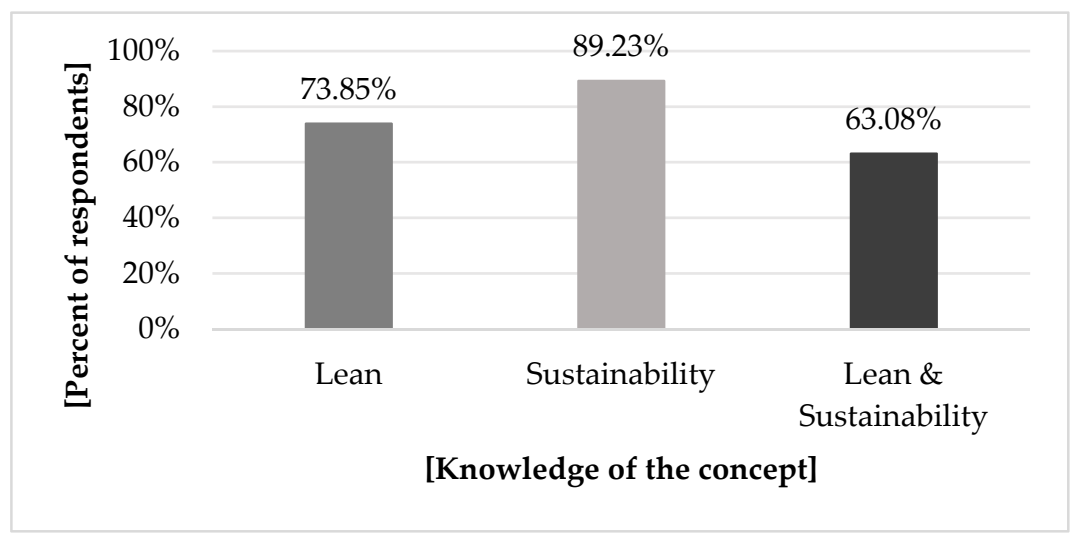

Figure 5. The percentage of respondents knowing the "lean" and "sustainability" concepts and both. 
In Table 8, we observe the small values of SD and SE describing a normal distribution in relation to the Mean, taking in consideration that we coded with " 1 " knowing the lean, sustainability, respectively both concepts, while with " 0 " not knowing the lean or sustainability concept, respectively knowing at least one. Our results clearly indicate that, statistically, there are more than $2 / 3$ respondent that have knowledge of one or both concepts.

Table 8. Descriptive statistics for the number of respondents knowing the "lean" and "sustainability" concepts.

\begin{tabular}{ccccccc}
\hline & $\mathbf{N}$ & Min. & Max. & \multicolumn{2}{c}{ Mean } & \multicolumn{2}{c}{ Std. Dev. } \\
\cline { 2 - 7 } & Statistic & Statistic & Statistic & Statistic & Std. Err. & Statistic \\
\hline Lean & 65 & 0 & 1 & 0.74 & 0.055 & 0.443 \\
Sustainability & 65 & 0 & 1 & 0.89 & 0.039 & 0.312 \\
Both & 65 & 0 & 1 & 0.63 & 0.060 & 0.486 \\
\hline
\end{tabular}

Our survey contained a structured question with predetermined answers regarding the particular "lean" and "sustainability" tools used (a total of 23 tools) by the respondents. Figure 6 presents the top seven "lean" and "sustainability" tools and we can observe that ISO Standards (75.38\%), 5S (64.62\%), and Problem Solving $(56.62 \%)$ are the most used tools in the interviewed companies. The other ones recorded over $40 \%$ of responses: Kaizen (47.69\%), Kanban (44.62\%), EMS-Environmental Management System (43.08\%), and Jidoka (41.54\%) and are entitled to be included in our top seven "lean" and "sustainability" tools used by respondents.

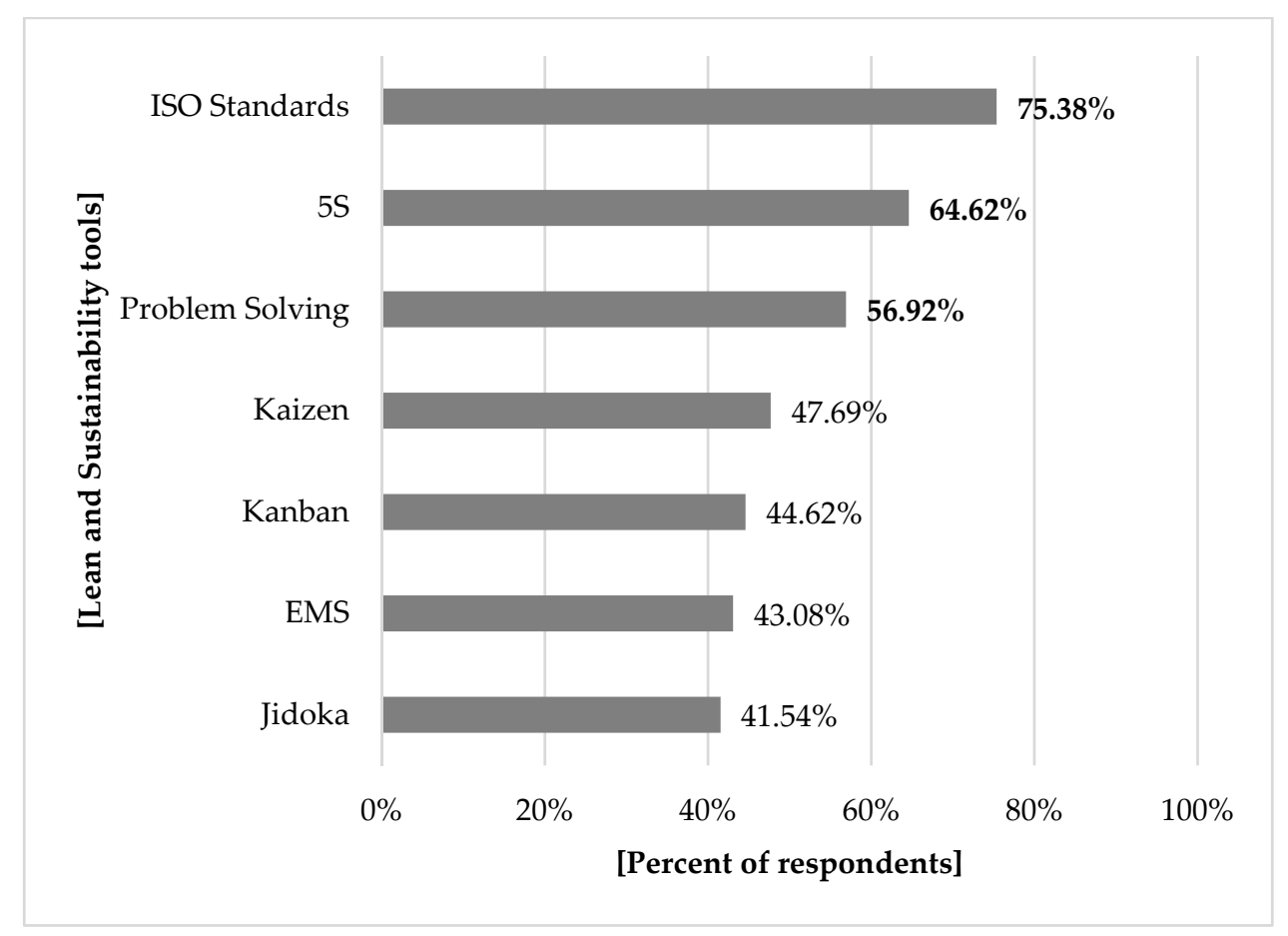

Figure 6. Top seven "lean" and "sustainability" tools used by respondents.

After coding our responses with " 1 " for "Yes, I use this tool" and " 0 " for "No, but it's implemented in the company", in Table 9 we can observe the relative small SD and SE values indicating that the responses are more concentrated around value " 1 ", thus can be included in the top seven "lean" and "sustainability" tools used by respondents. 
Table 9. Descriptive statistics for the top seven "lean" and "sustainability" tools used by respondents.

\begin{tabular}{ccccccc}
\hline & $\mathbf{N}$ & Min. & Max. & \multicolumn{2}{c}{ Mean } & Std. Dev. \\
\cline { 2 - 6 } & Statistic & Statistic & Statistic & Statistic & Std. Err. & Statistic \\
\hline ISO Standards & 65 & 0 & 1 & 0.75 & 0.054 & 0.434 \\
5S & 65 & 0 & 1 & 0.65 & 0.060 & 0.482 \\
Problem Solving & 65 & 0 & 1 & 0.57 & 0.062 & 0.499 \\
Kaizen & 65 & 0 & 1 & 0.48 & 0.062 & 0.503 \\
Kanban & 65 & 0 & 1 & 0.45 & 0.062 & 0.501 \\
EMS & 65 & 0 & 1 & 0.43 & 0.062 & 0.499 \\
Jidoka & 65 & 0 & 1 & 0.42 & 0.062 & 0.497 \\
\hline
\end{tabular}

The same structured question with predetermined answers regarding "lean" and "sustainability" tools shows the ones not particular used by respondents but implemented in the company. Thus, Figure 7 presents the top seven "lean" and "sustainability" tools not particular used by respondents but implemented in the company. We can observe that Kaikaku (89.23\%), SMED-Single-Minute Exchange of Dies (83.08\%), and Six Sigma (81.54\%) are the most implemented tools, while six of them: JIT (Just in Time), Bottleneck Analysis, SFM (Shop Floor Management), GRI (Global Report Initiative), EMAS (Eco Management and Audit Scheme), and RECP (Resource Efficient and Cleaner Production) record the same value $(78.46 \%)$.

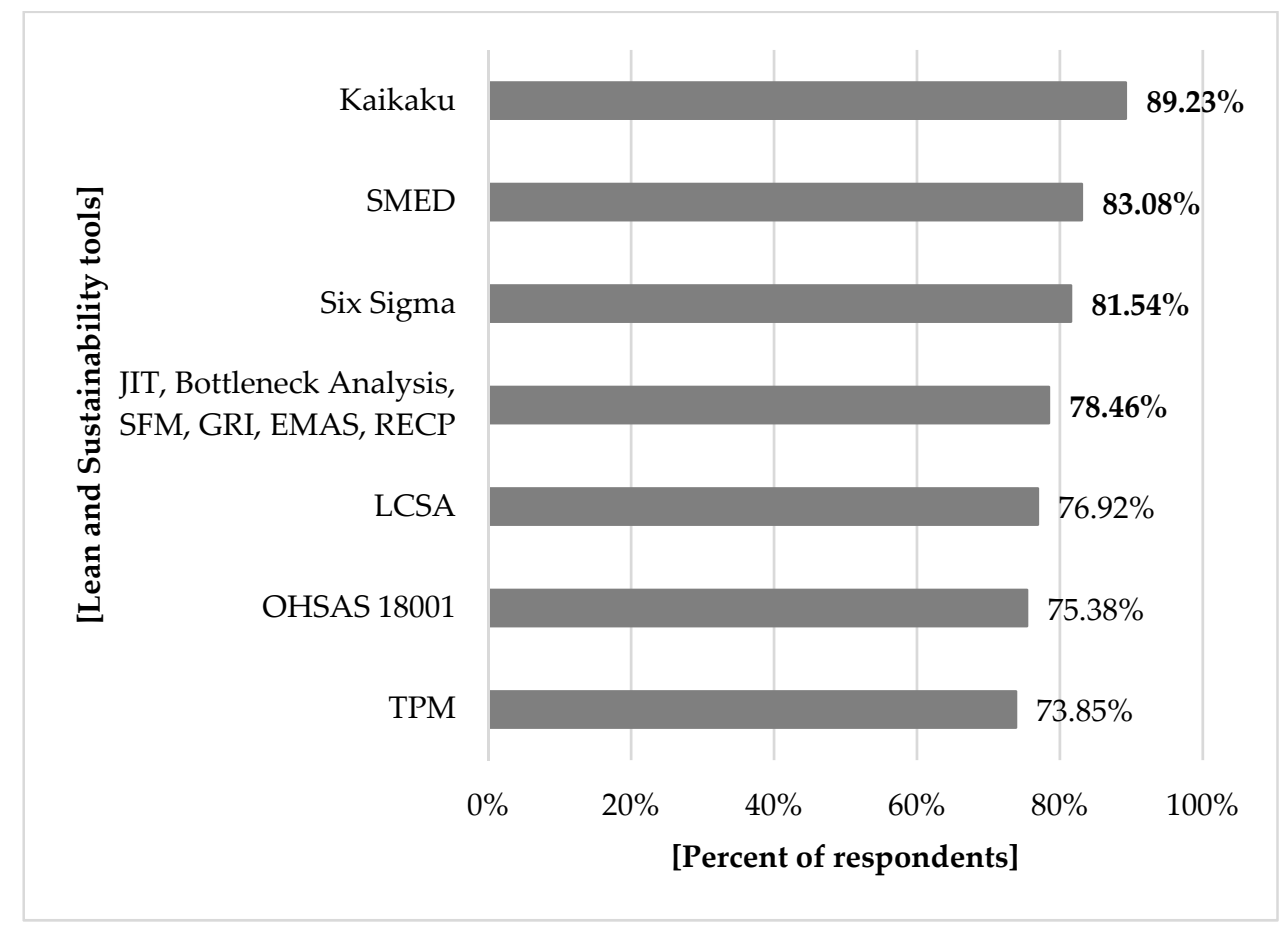

Figure 7. Top seven "lean" and "sustainability" tools not used particularly by respondents but implemented in the company.

Using the same responses coding principle, as mentioned above, in Table 10 we present the computed values of the SD, SE and Mean for the tools included in the top seven "lean" and "sustainability" tools not used by respondents but implemented in the company. The small values of the Mean indicate that the responses are more concentrated around value " 0 ", meaning that the tools are not particularly used by respondents, but they do have knowledge of them being used in the company. 
Table 10. Descriptive statistics for the top seven "lean" and "sustainability" tools not used by respondents but implemented in the company.

\begin{tabular}{ccccccc}
\hline & $\mathbf{N}$ & Min. & Max. & \multicolumn{2}{c}{ Mean } & Std. Dev. \\
\cline { 2 - 6 } & Statistic & Statistic & Statistic & Statistic & Std. Err. & Statistic \\
\hline Kaikaku & 65 & 0 & 1 & 0.11 & 0.039 & 0.312 \\
SMED & 65 & 0 & 1 & 0.17 & 0.047 & 0.378 \\
Six Sigma & 65 & 0 & 1 & 0.18 & 0.048 & 0.391 \\
JIT & 65 & 0 & 1 & 0.22 & 0.051 & 0.414 \\
Bottleneck Analysis & 65 & 0 & 1 & 0.22 & 0.051 & 0.414 \\
SFM & 65 & 0 & 1 & 0.22 & 0.051 & 0.414 \\
GRI & 65 & 0 & 1 & 0.22 & 0.051 & 0.414 \\
EMAS & 65 & 0 & 1 & 0.22 & 0.051 & 0.414 \\
RECP & 65 & 0 & 1 & 0.22 & 0.051 & 0.414 \\
LCSA & 65 & 0 & 1 & 0.23 & 0.053 & 0.425 \\
OHSAS 18001 & 65 & 0 & 1 & 0.25 & 0.054 & 0.434 \\
TPM & 65 & 0 & 1 & 0.26 & 0.055 & 0.443 \\
\hline
\end{tabular}

Figure 8 presents (a) the percentage of respondents receiving training for the lean tools used $(52.31 \%)$, while (b) for the ones receiving training for the sustainability tools used (36.91\%), showing that the distribution for receiving and not receiving training are all most the same (50-50\%).

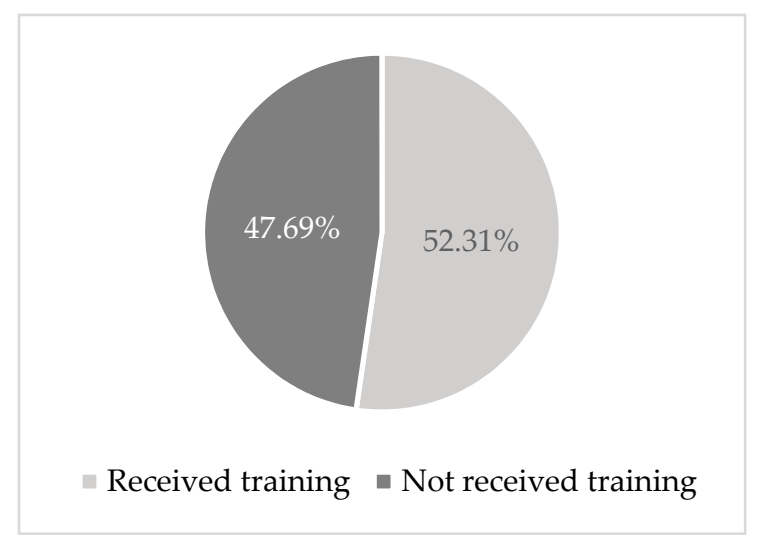

(a)

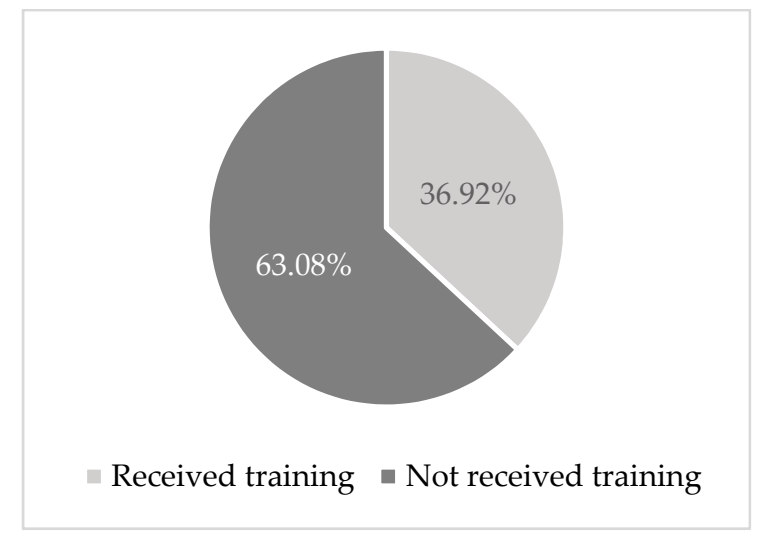

(b)

Figure 8. Percentage of respondents receiving training for the used tools: (a) Lean tools; and (b) sustainability tools.

Table 11 show the distribution of respondents being trained for the "lean" and "sustainability" tools they use. We coded their answers with the following values: " 1 " for receiving training and " 0 " for not receiving values. Looking at the mean, SE, and SD values we observe that the answers are divided almost evenly between "receiving training" and "not receiving training".

Table 11. Descriptive statistics for respondents receiving training for the used "lean" and "sustainability" tools.

\begin{tabular}{ccccccc}
\hline & $\mathbf{N}$ & Min. & Max. & \multicolumn{2}{c}{ Mean } & Std. Dev. \\
\cline { 2 - 7 } & Statistic & Statistic & Statistic & Statistic & Std. Err. & Statistic \\
\hline Lean tools training & 65 & 0 & 1 & 0.52 & 0.062 & 0.503 \\
$\begin{array}{c}\text { Sustainability tools } \\
\text { training }\end{array}$ & 65 & 0 & 1 & 0.37 & 0.060 & 0.486 \\
\hline
\end{tabular}

Figure 9 presents the percentage of respondents by the type of training received for the used "lean" and "sustainability" tools. A standing out observations is that $44.62 \%$ did not receive training or we 
recorded missing values, while $29.23 \%$ received internal company training, and others are self-taught $(6.15 \%)$.

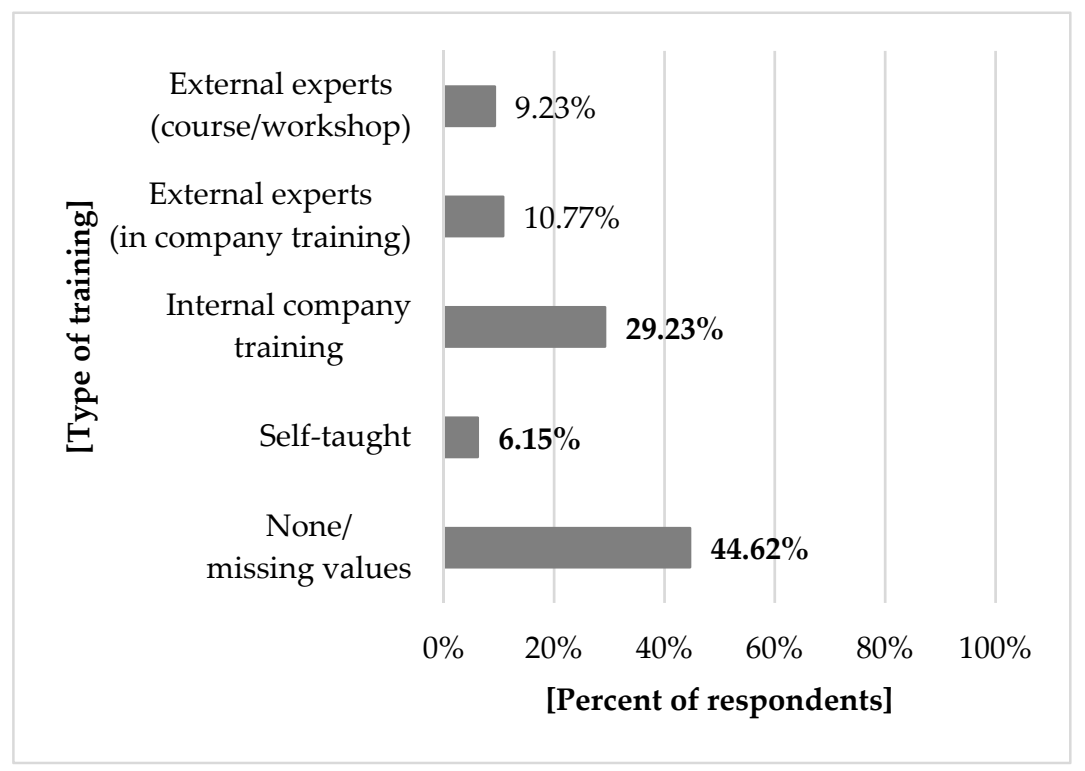

Figure 9. The percentage of respondents based on type of training received for the used tools.

To analyze the type of training received for the used methods, Table 12, we agreed on five possible answers: "0" for none/missing values, " 1 " for self-taught", " 2 " for in house training/in company training, " 3 " for external experts—in house training and " 4 " for external experts—course/workshop. The relative high values of the mean (1.34) and SD (1.384) suggest that the answers are concentrated around no training received/missing values.

Table 12. Descriptive statistics for the number of respondents based on the type of training received for the tools (own calculation).

\begin{tabular}{ccccccc}
\hline & N & Min. & Max. & \multicolumn{2}{c}{ Mean } & \multicolumn{2}{c}{ Std. Dev. } \\
\cline { 2 - 6 } & Statistic & Statistic & Statistic & Statistic & Std. Err. & Statistic \\
\hline $\begin{array}{c}\text { Training methods } \\
\text { used }\end{array}$ & 65 & 0 & 4 & 1.34 & 0.172 & 1.384 \\
\hline
\end{tabular}

We provided the list of the 17 Sustainable Development Goals (for reference see Table 1) in order to find out if they are pursued by the company. Thus, Figure 10 reports the top seven goals identified as pursued by the company and we observed that the main pursued goals are: decent work and economic growth (69.23\%); industry innovation and infrastructure (64.62\%); and responsible consumption and production $(61.54 \%)$.

Out of the 17 Sustainable Development Goals presented in the first part of our paper (Table 1), we identify the top seven Sustainable Development Goals pursued by companies involved in our study, based on a frequency of appearance analysis. To analyze the distribution of our answers we coded with " 0 " for "No, it isn't an objective of the company", " 1 " for "Yes, it's an objective of the company" and " 2 " for "I don't have knowledge about this". The values of the mean and SD indicate that the answers are more concentrated around value 1 , thus the seven goals can be included in our top, Table 13. 


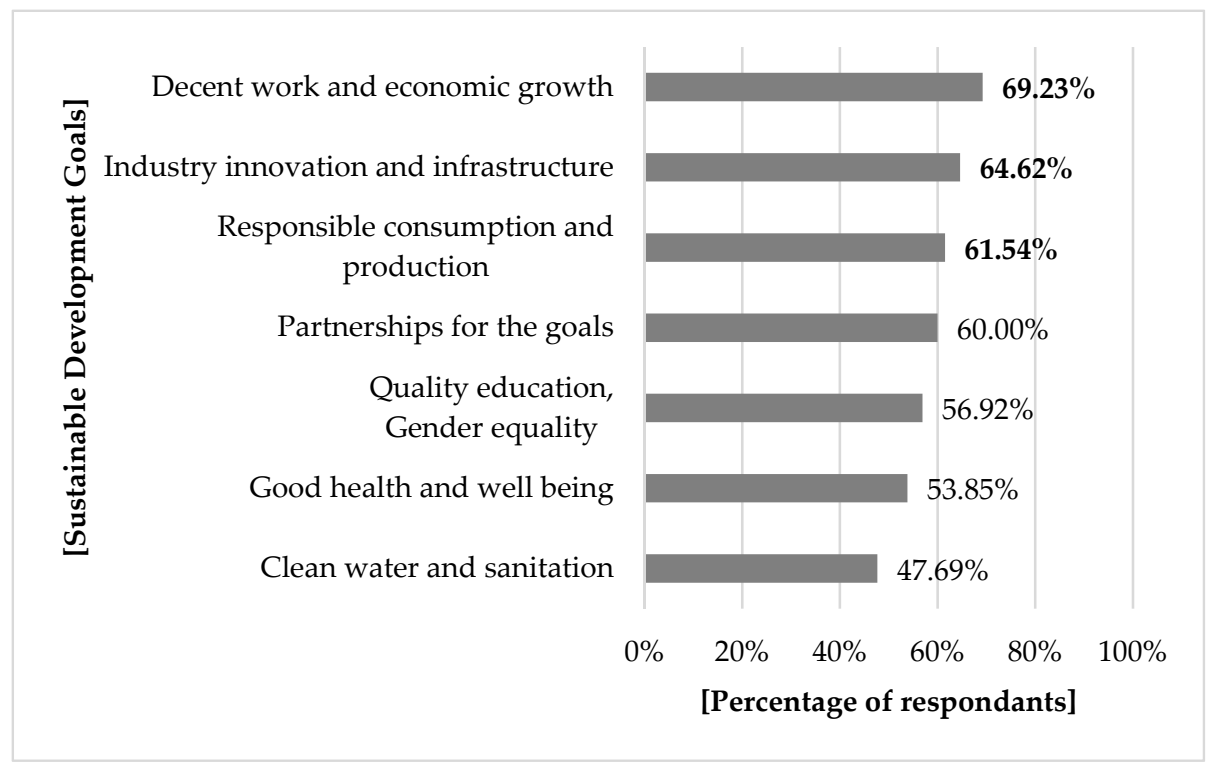

Figure 10. Top seven Sustainable Development Goals pursued by the respondents' company.

Table 13. Descriptive statistics for the top seven Sustainable Development Goals pursued by the respondents' company.

\begin{tabular}{ccccccc}
\hline & $\mathbf{N}$ & Min. & Max. & \multicolumn{2}{c}{ Mean } & Std. Dev. \\
\cline { 2 - 7 } & Statistic & Statistic & Statistic & Statistic & Std. Err. & Statistic \\
\hline $\begin{array}{c}\text { Decent work and economic growth } \\
\text { Industry innovation and }\end{array}$ & 65 & 0 & 2 & 0.88 & 0.068 & 0.545 \\
$\quad \begin{array}{c}\text { infrastructure } \\
\text { Responsible consumption and }\end{array}$ & 65 & 0 & 2 & 0.86 & 0.072 & 0.583 \\
$\quad$ production & 65 & 0 & 2 & 0.86 & 0.076 & 0.609 \\
Partnerships for the goals & 65 & 0 & 2 & 0.94 & 0.079 & 0.634 \\
$\quad$ Quality education & 65 & 0 & 2 & 0.91 & 0.081 & 0.655 \\
$\quad$ Gender equality & 65 & 0 & 2 & 0.82 & 0.079 & 0.635 \\
Good health and well being & 65 & 0 & 2 & 0.85 & 0.083 & 0.667 \\
$\quad$ Climate action & 65 & 0 & 2 & 0.68 & 0.093 & 0.752 \\
\hline
\end{tabular}

Figure 11 presents (a) the percentage of respondents considering lean tools useful for the company $(72.31 \%)$, while (b) the percentage of respondents considering sustainability tools useful for the company $(84.62 \%)$, showing a mainly positive perception upon the overall usefulness on the tools.

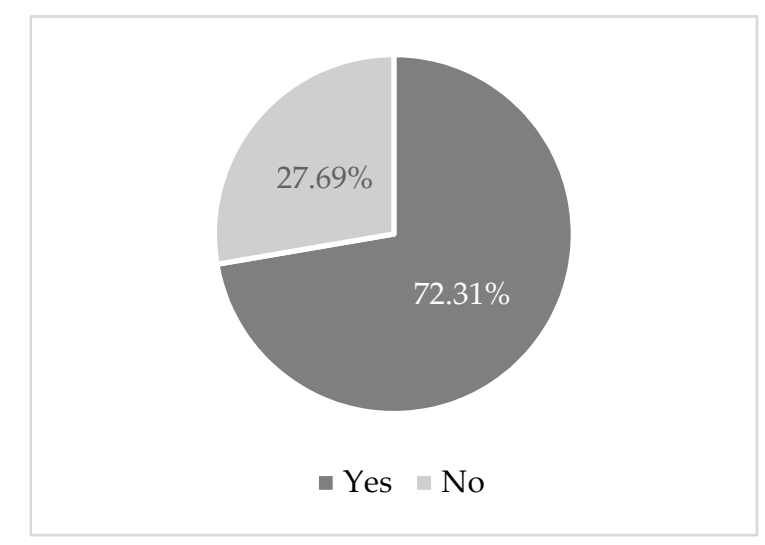

(a)

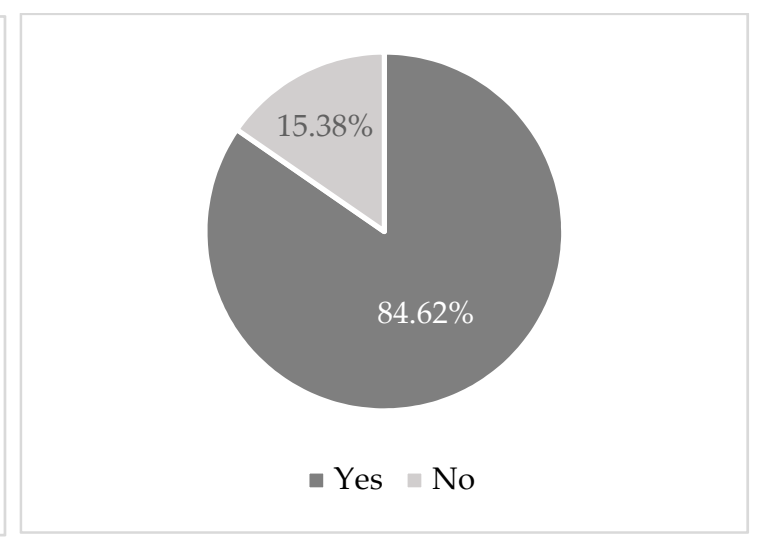

(b)

Figure 11. Percentage of respondents considering the concepts useful for the company: (a) Lean; and (b) sustainability. 
Being a dichotomic response question, we coded the answers with " 0 " for not considering the tools useful, and " 1 " for considering the tools useful, thus the mean $(0.72$, respectively 0.85$)$ and SD (0.451, respectively 0.364 ) show that the answers are concentrate around value 1 , indicating a large number of respondents considering the tools useful for their company (see Table 14).

Table 14. Descriptive statistics for the respondents considering the concepts useful for the company.

\begin{tabular}{ccccccc}
\hline & $\mathbf{N}$ & Min. & Max. & \multicolumn{2}{c}{ Mean } & \multicolumn{2}{c}{ Std. Dev. } \\
\cline { 2 - 7 } & Statistic & Statistic & Statistic & Statistic & Std. Err & Statistic \\
\hline $\begin{array}{c}\text { Considering "lean" tools useful } \\
\text { Considering "sustainability" } \\
\text { tools useful }\end{array}$ & 65 & 0 & 1 & 0.72 & 0.056 & 0.451 \\
\hline
\end{tabular}

Using a five-point Likert Scale Figure 12 presents the cumulative percentage of high and maximum values for the order of each benefits in the companies' activity based on respondents' perception: quality assurance $(89.23 \%)$, working standards $(81.54 \%)$, and visual management $(78.46 \%)$ being the top activities in which "lean" and "sustainability" tool implementation brought benefits.

Based on our five-point Likert scale, the high mean and SD values, Table 15, indicate that responses are concentrated around high and maximum values (4 and 5, respectively) based on respondents' perception upon the activities in which "lean" and "sustainability" tool implementation brought benefits.

Table 15. Descriptive statistics for company activity benefits after tool implementation, based on respondents' perceptions.

\begin{tabular}{ccccccc}
\hline & $\mathbf{N}$ & Min. & Max. & \multicolumn{2}{c}{ Mean } & \multicolumn{1}{c}{ Std. Dev. } \\
\cline { 2 - 7 } & Statistic & Statistic & Statistic & Statistic & Std. Err. & Statistic \\
\hline Stocks & 65 & 1 & 5 & 3.74 & 0.139 & 1.122 \\
Suppliers & 65 & 2 & 5 & 3.86 & 0.109 & 0.882 \\
Maintenance & 65 & 1 & 5 & 4.02 & 0.127 & 1.023 \\
Production planning & 65 & 1 & 5 & 4.05 & 0.131 & 1.052 \\
Team & 65 & 1 & 5 & 4.09 & 0.120 & 0.964 \\
Working processes & 65 & 1 & 5 & 4.11 & 0.126 & 1.017 \\
Visual management & 65 & 2 & 5 & 4.15 & 0.103 & 0.833 \\
Working standards & 65 & 2 & 5 & 4.28 & 0.109 & 0.875 \\
Quality & 65 & 2 & 5 & 4.45 & 0.096 & 0.771 \\
\hline
\end{tabular}

Using a five-point Likert Scale Figure 13 presents the cumulative percentage of high and maximum values for respondents' perception upon each overall company benefit brought by "lean" and "sustainability" tool implementation. Since some company benefits reported the same value, we placed them in groups. Focusing on the first three groups of benefits: Process and Material Losses Reduction, Increasing Resource Efficiency and Customer Satisfaction (83.08\%), Cost Reduction and Increasing Product Quality $(80.00 \%)$, and Productivity Improvement and Company Image Improvement $(78.46 \%)$ we can also consider them high priority objectives for the overall company activity and the main reason for which companies implement "lean" and "sustainability" tools. 


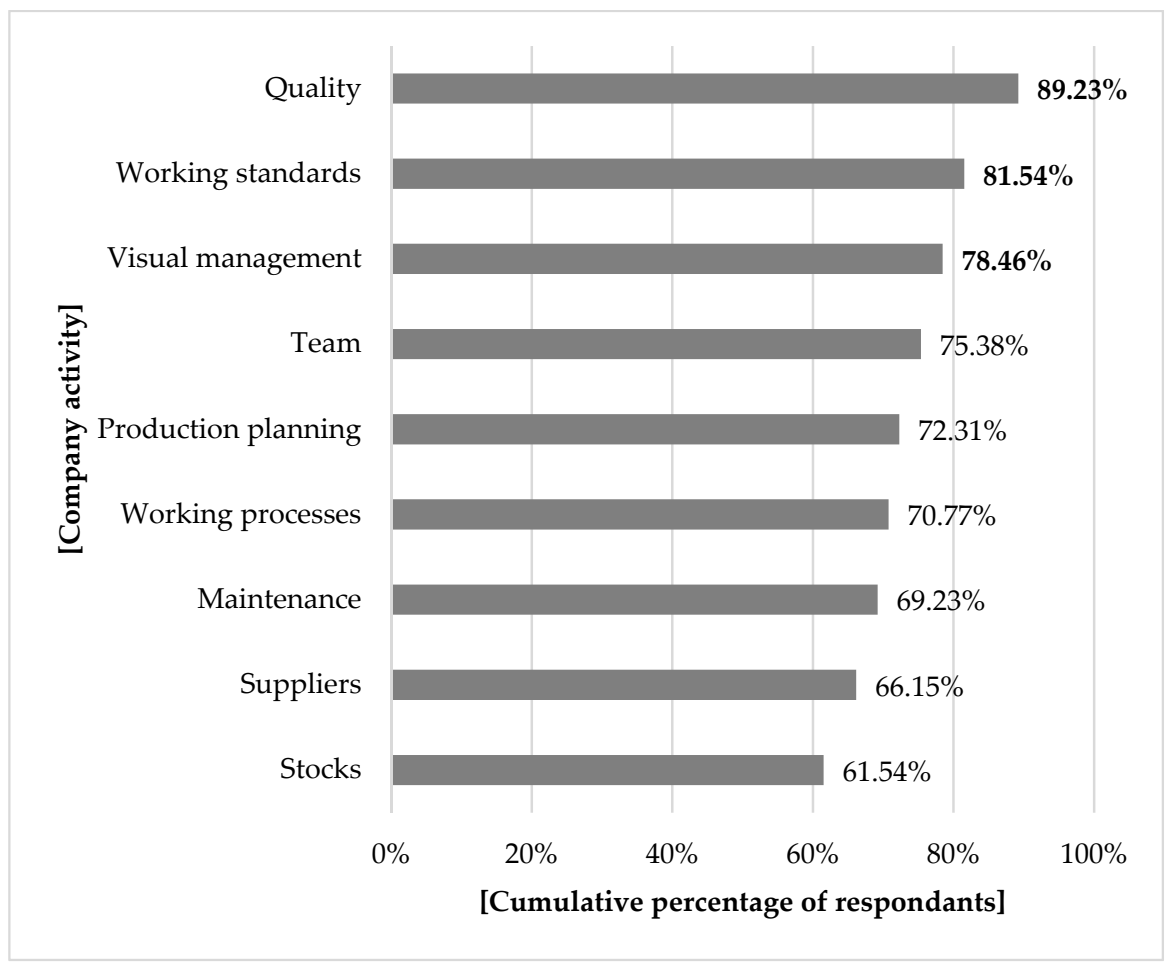

Figure 12. Company activity benefits after tool implementation, based on respondents' perceptions.

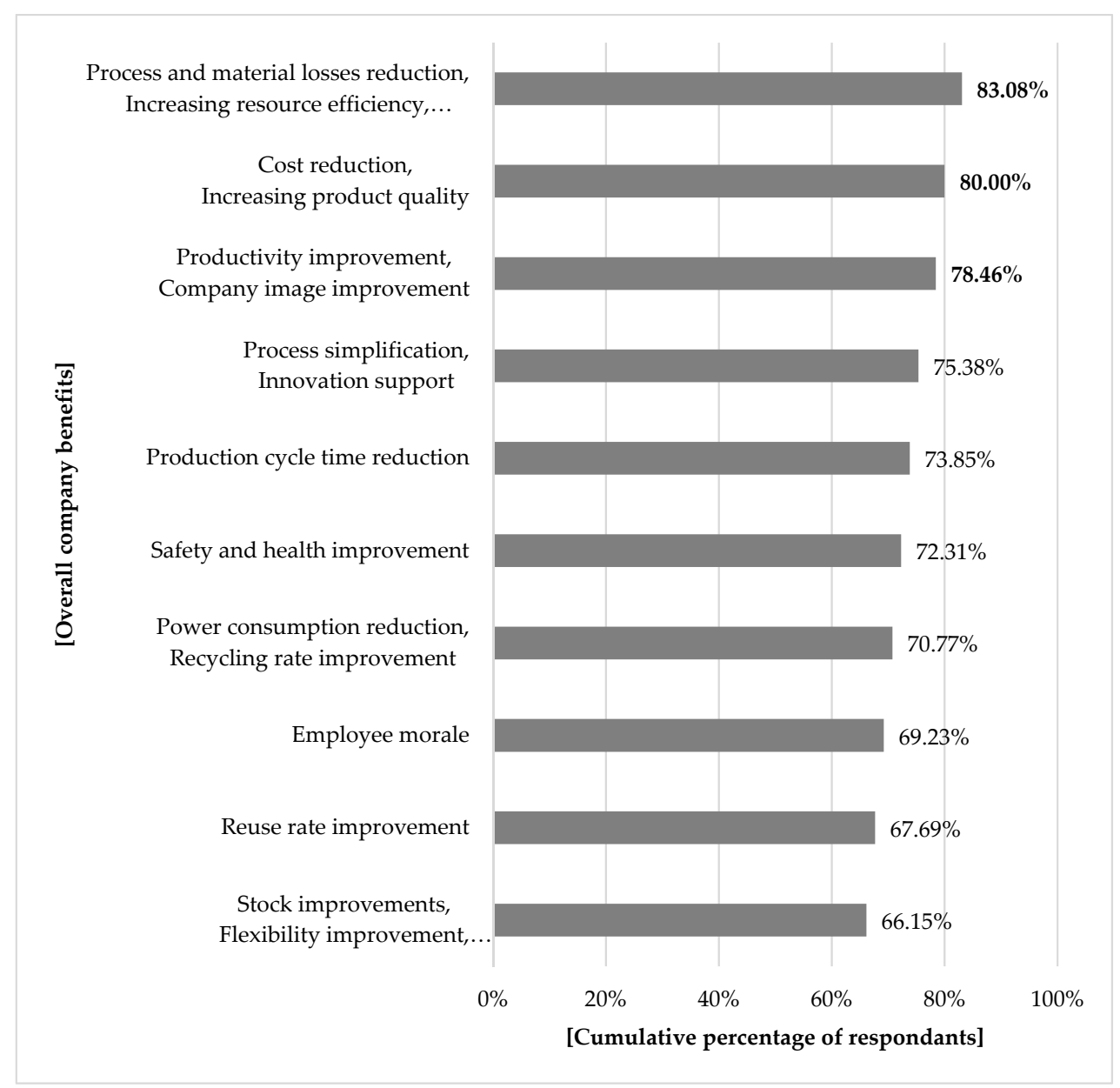

Figure 13. Top 10 overall company benefits based on respondents' perception. 
Using the same responses coding principle for the five-point Likert scale, as mentioned above, in Table 16 we present the computed values of the SD, SE, and mean for the top overall company benefits brought by the "lean" and "sustainability" tools implementation and observed by the company employees. the high mean and SD values indicate that responses are concentrate around high and maximum values (4 and 5, respectively) based on respondents' perceptions upon the observed overall company benefits.

Table 16. Descriptive statistics for the top 10 overall company benefits based on respondents' perceptions.

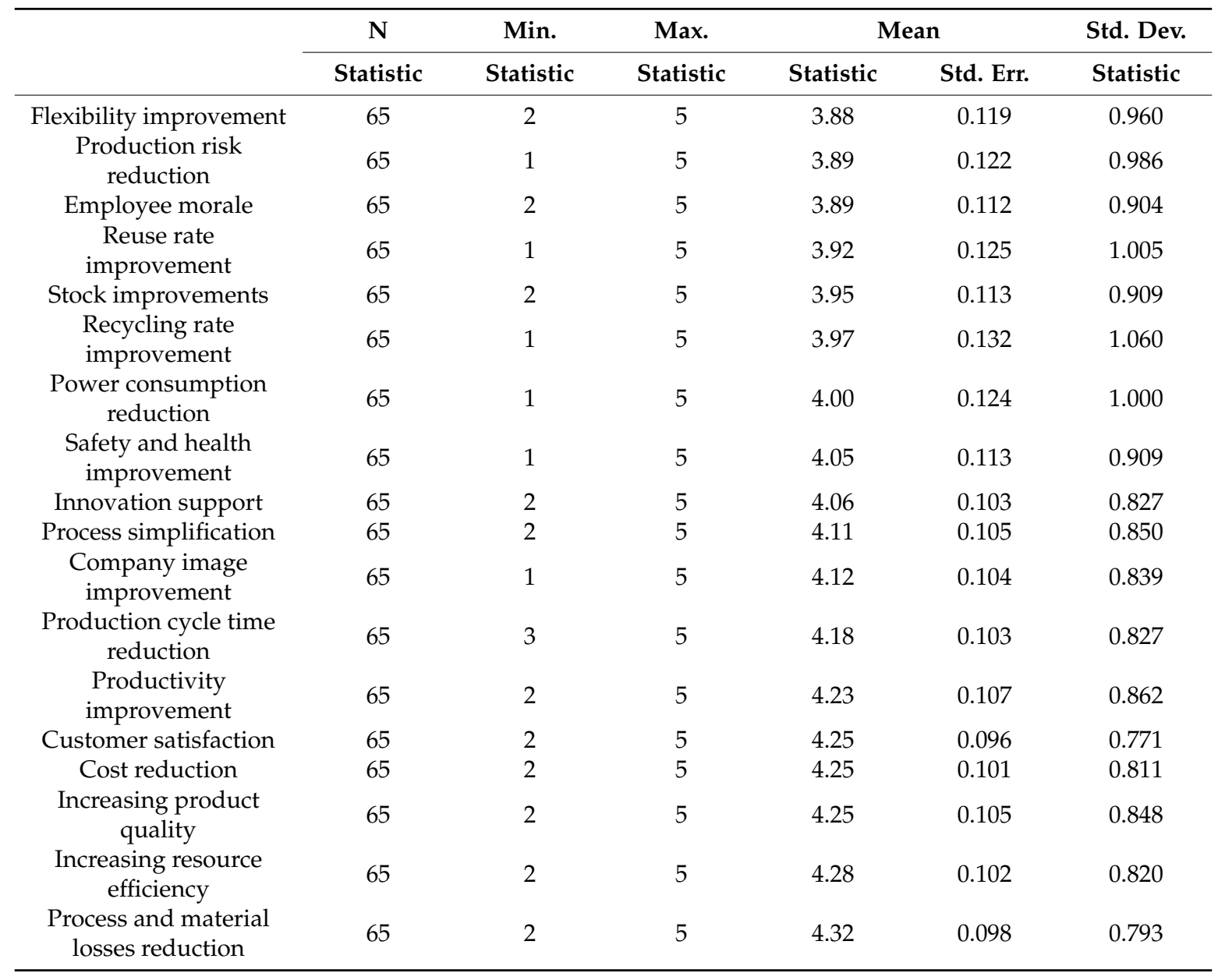

Recoding our five-point Likert scale to a three-point Likert scale for a better view of the results, Figure 14 presents the frequencies of appearance for the most common drawbacks in the company's activity. From our respondents' experience, the most common drawbacks with low frequency appearance are: Over-production (46.15\%), Transport (46.15\%), Material or Product Stocks (43.08\%), Over-processing $(41.54 \%)$ and Motion (41.54\%), while the most drawbacks with high frequency of appearance are Waiting $(46.16 \%)$ and Defects or Scrap $(40.00 \%)$. 


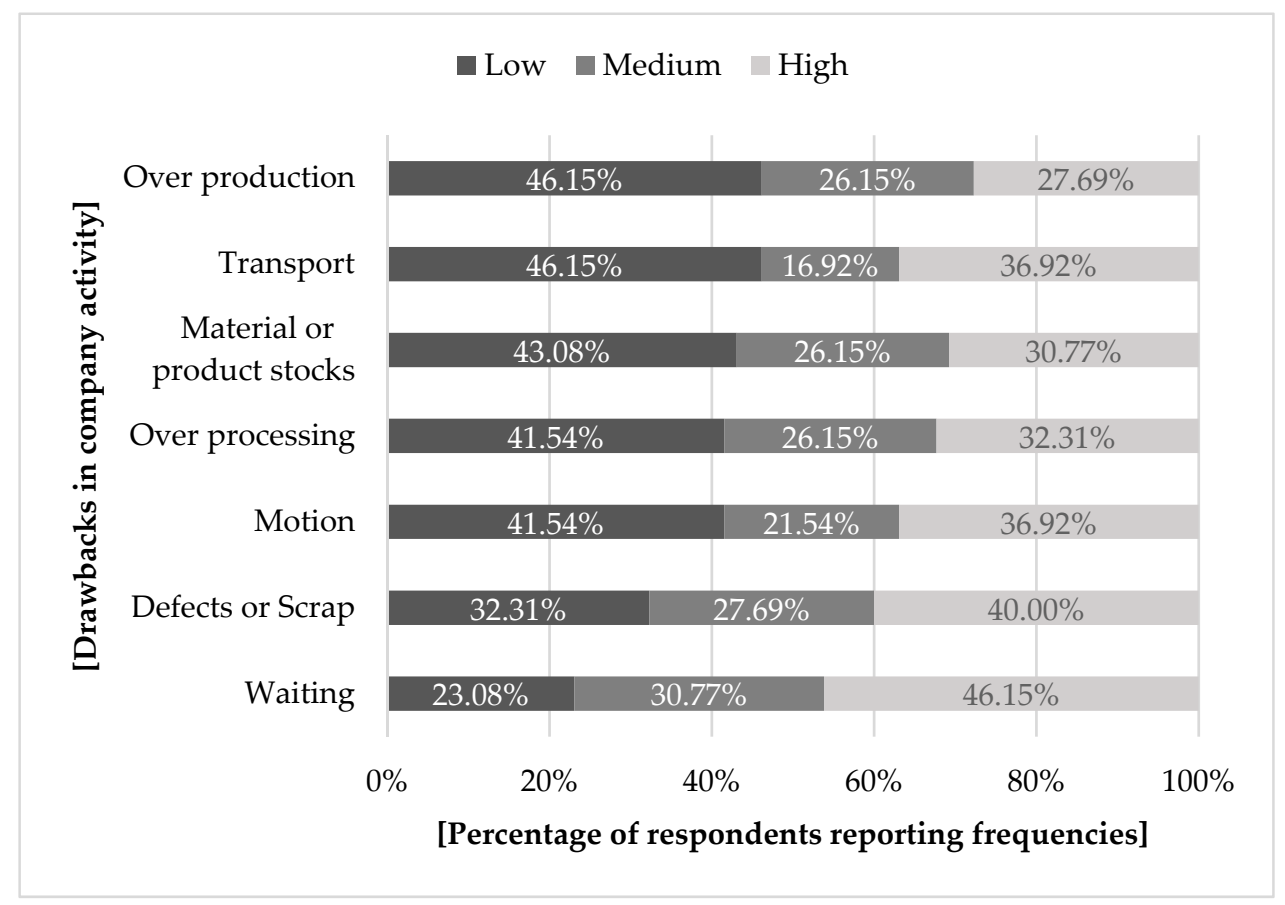

Figure 14. Drawback frequencies in company's activity based on respondents' experiences.

Based on our observations, the high mean and SD values, Table 17, indicate that the answers regarding the company's activity drawback frequencies are concentrated around the middle area, with two of them being in the high and maximum area ("Defect or Scrap" and "Waiting") thus probably influenced by the company's business industry sector. For a better understanding of our results see Figure 14, in which we recoded our five-point Likert scale to a three-point Likert scale.

Table 17. Descriptive statistics for drawback frequencies in company's activity based on respondents' experiences (own calculation).

\begin{tabular}{ccccccc}
\hline & $\mathbf{N}$ & Min. & Max. & \multicolumn{2}{c}{ Mean } & Std. Dev. \\
\cline { 2 - 7 } & Statistic & Statistic & Statistic & Statistic & Std. Err. & Statistic \\
\hline Over production & 65 & 1 & 5 & 2.55 & 0.171 & 1.381 \\
Transport & 65 & 1 & 5 & 2.72 & 0.175 & 1.409 \\
Material or product stocks & 65 & 1 & 5 & 2.75 & 0.149 & 1.199 \\
Over processing & 65 & 1 & 5 & 2.78 & 0.163 & 1.317 \\
Motion & 65 & 1 & 5 & 2.91 & 0.161 & 1.296 \\
Defects or Scrap & 65 & 1 & 5 & 3.06 & 0.162 & 1.310 \\
Waiting & 65 & 1 & 5 & 3.45 & 0.154 & 1.238 \\
\hline
\end{tabular}

From Figure 15 we can observe that a high percentage of respondents have the knowledge of an annual sustainability report out of which $26.15 \%$ use an unstandardized report, while $30.77 \%$ create a standardized report based on the GRI (Global Report Initiative) recommendations. The rest of the respondents replied that the company does not create an annual sustainability report $(7.69 \%)$ and a considerable percent replied as not having knowledge about all of the company's annual reports $(35.38 \%)$. 


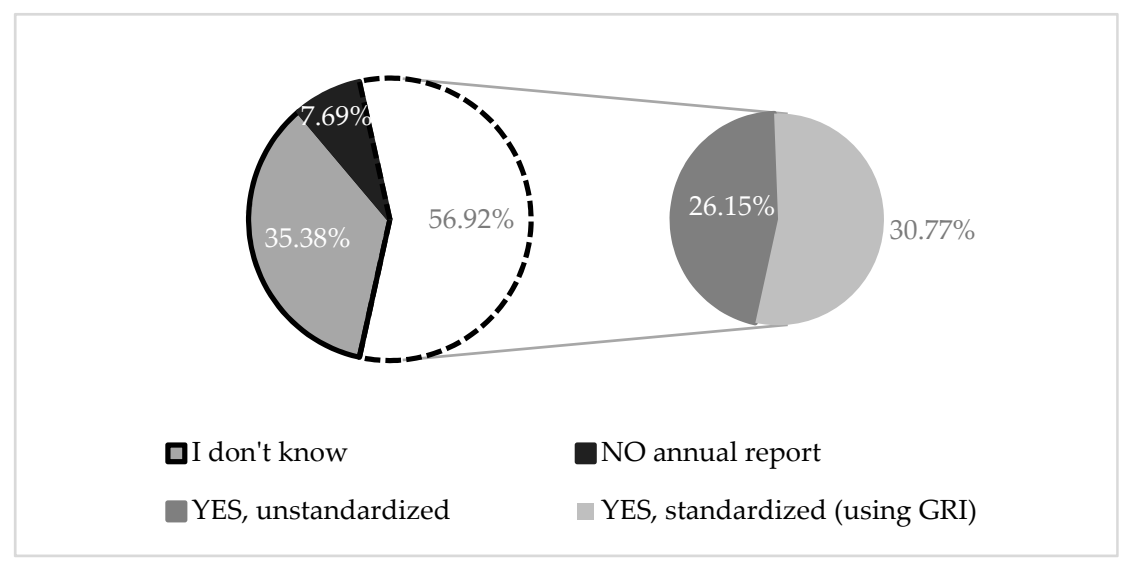

Figure 15. The existence of an annual sustainability company report based on respondents' answer.

To observe the existence of an annual sustainability report in the company we agreed on five possible answers: " 0 " for "No annual report", "1" for "Yes, standardized (using GRI)", "2" for "YES, unstandardized" and " 3 " for "I don't know". The relative high values of the mean (1.89) and SD (0.986) suggest that the answers are concentrated around existing an annual report standardized or not, Table 18. Another thing that the values suggest it that a considerable amount of respondent do not have knowledge about an existing report. For a better understanding of our results see Figure 15.

Table 18. Descriptive statistics for the existence of an annual sustainability company report based on respondents' answers.

\begin{tabular}{ccccccc}
\hline & $\mathbf{N}$ & Min. & Max. & Mean & & Std. Dev. \\
\cline { 2 - 6 } & Statistic & Statistic & Statistic & Statistic & Std. Err. & Statistic \\
\hline $\begin{array}{c}\text { Company annual } \\
\text { sustainability report }\end{array}$ & 65 & 0 & 3 & 1.89 & 0.122 & 0.986 \\
\hline
\end{tabular}

\section{Proposal for a New Method and Enterprise Game}

The new instrument/game proposed (developed by the authors) can be described using the MOSTO model (Mission, Objectives, Strategy, Tactics, and Operationalization) as follows:

- Mission: Raise awareness regarding the necessity for improvement of anyone's activity in order to be competitive and sustainable.

- Objectives: To decrease/eliminate non-value-added activities (wastes) and increase value-added activities.

- Strategy: Integrated use of lean and sustainability tools.

- Tactics: Use of enterprise games which integrate lean and sustainability tools.

- Operationalization: Using the SLIM game.

Playing this game will allow players: to participate to actual enterprise processes, to evaluate the process, to identify value added and non-value-added activities, to reduce/eliminate non-value-added activities and improve value-added activities, redesign the processes to eliminate wastes, apply lean and sustainability tools, and measure the efficiency of proposed solution through an aggregated indicator (SLIM indicator). The SLIM game flowchart is presented in Figure 16. To explain in more details the algorithm of our game, we present the Figure 17. 


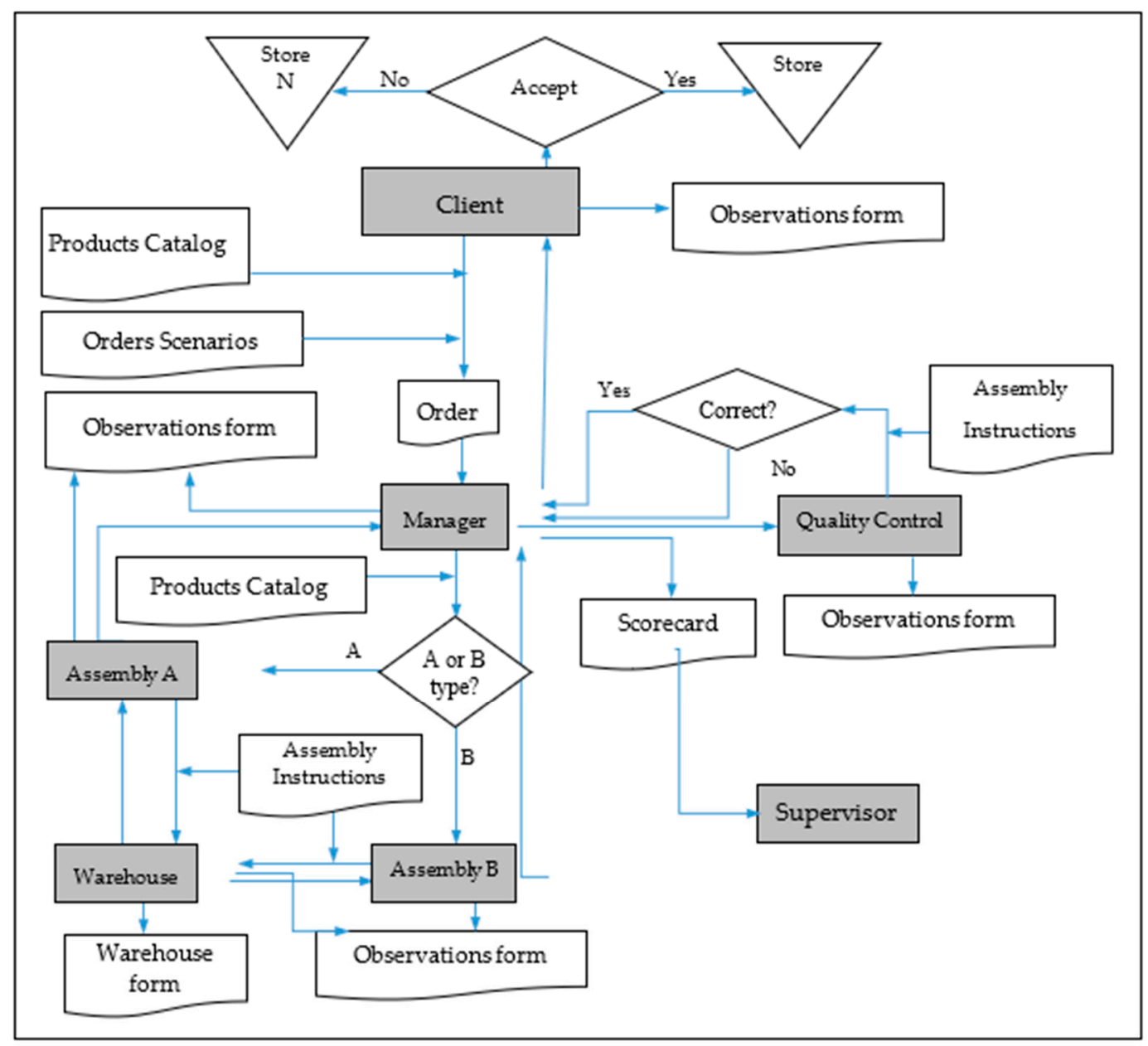

Figure 16. SLIM game flowchart.

The game proposes a number of posts to cover the flow of production to meet client demands, and also the client. This includes: a warehouse for parts required for production/assembly (plastic building blocks), the production processes (assembling the parts), quality control, the manager and the client, but also the supervisor (who should be trained before the game started, or it should be one who has previously played the game). Each post will receive the job description sheet and all the forms required for the activity.

There should be at least two rounds (a round simulates a production shift/day). This is in order to compare the results of the rounds, based on proposed indicators, but also on the basis of the players' suggestions filed in the observations form.

We propose a SLIM aggregate index (SLIMx) that includes loss reduction and improvements using lean and sustainability tools. The SLIMx index is measured in points and, like in a game, more points means the system/activity is more "slim". The formula for SLIMx was finalized and validated after the game was tested (see the game test phase section), and it is presented in Equation (1):

$$
\mathrm{SLIMx}_{\mathrm{i}}=\mathrm{NPD}_{\mathrm{i}}+0 \mathrm{RC}_{\mathrm{i}}+0 \mathrm{QC}_{\mathrm{i}}+\mathrm{I}_{\mathrm{PCT}(\Delta \mathrm{i})}+\mathrm{I}_{\mathrm{W}(\Delta \mathrm{i})}+\mathrm{I}_{\mathrm{SC}}(\mathrm{pts}) \rightarrow \text { maxim }
$$

where:

SLIMx $_{\mathrm{i}}=$ SLIM index for round $\mathrm{i}(\mathrm{pts})$;

$\mathrm{NPD}_{\mathrm{i}}=$ Number of Products Delivered to Client in round $\mathrm{i}(\mathrm{pts})$, where 1 piece $=1$ point; and 
$0 \mathrm{RC}_{\mathrm{i}}=$ Indicator of "Zero Rejected Products by Client" (pts) (Equation (2)):

$$
O R C_{i}= \begin{cases}5, & \text { client rejected products }=0 \\ 0, & \text { client rejected products } \neq 0\end{cases}
$$

$0 C_{\mathrm{i}}=$ Indicator of "Zero Products Not Passing Quality Control" (pts) (Equation (3)):

$$
0 Q C_{i}= \begin{cases}5, & \text { products not passing Quality Control }=0 \\ 0, & \text { products not passing Quality Control } \neq 0\end{cases}
$$

$\mathrm{I}_{\mathrm{PCT}(\Delta \mathrm{i})}=$ Indicator of Production Cycle Time (PCT) improvement (decrease) from the previous round, calculated from the second round on Equation (4):

$$
\begin{gathered}
I_{P C T(\Delta \mathrm{i})}=\left\{\begin{array}{cc}
5, & 20 \%<\text { PCT improvement } \\
3, & 10 \%<\text { PCT improvement } \leq 20 \% \\
1, & 0 \%<\text { PCT improvement } \leq 10 \% \\
0, & P C T \text { improvement }=0 \%
\end{array}\right. \\
\text { PCT improvement }=\frac{P C T_{i-1}-P C T_{i}}{P C T_{i-1}} \cdot 100
\end{gathered}
$$

$\mathrm{I}_{\mathrm{WP}(\Delta \mathrm{i})}=$ Indicator of Workforce Productivity (WP) improvement (increase) from the previous round, calculated from the second round on Equation (6):

$$
\begin{gathered}
I_{W P(\Delta \mathrm{i})}=\left\{\begin{array}{cc}
5, & 20 \%<\text { WP improvement } \\
3, & 10 \%<\text { WP improvement } \leq 20 \% \\
1, & 0 \%<\text { WP improvement } \leq 10 \% \\
0, & W P \text { improvement }=0 \%
\end{array}\right. \\
\text { WP improvement }=\frac{W P_{i}-W P_{i-1}}{W P_{i-1}} \cdot 100
\end{gathered}
$$

$\mathrm{I}_{\mathrm{SC}}=$ indicator for Standard Compliant Activity (pts), which measures the players' activity with respect to the standards in place (procedure, rules, work instructions on job description, fill in necessary forms completely and correctly).

This last indicator is an objective one and is estimated by the supervisor, using a scale from $0-5$ (from "not at all compliant" to "totally compliant"). All other indicators are objective and can be calculated from scorecard form (by who play the manager role or anybody else appointed by the manager). From the indicator formula, we can see that SLIM index can be as minimum as 0 (activity is not "slim") and can go more than 10 point for round one, and 20+ for further rounds.

During each round, and between rounds, players are encouraged to write down all the problems/inconsistencies encountered in their activity, as well as possible solutions to resolve problems and for improvement. To analyze and improve the activity it is intended to propose players to use known lean and sustainability tools. The most useful tools would be here: Kaizen, 5S, Poka Yoke, Bottleneck Analysis, 7 Wastes, LCA (Life Cycle Assessment), Eco-design, Learning curve, Pull systems, and Problem solving (Trial and Error Method). From these tools students are successfully applying the following: improve each time you can (does not matter how little), sort, set in order, clean, standardize (make rules and follow them), make a habit of doing the right and only the right activity, the right way and at right time, analyzing all types of waste possible, make time to analyze the activity (player's own activity and the entire game activity), and try new ways of doing it (even if will not leading to improvement, using the trial and error learning method). 


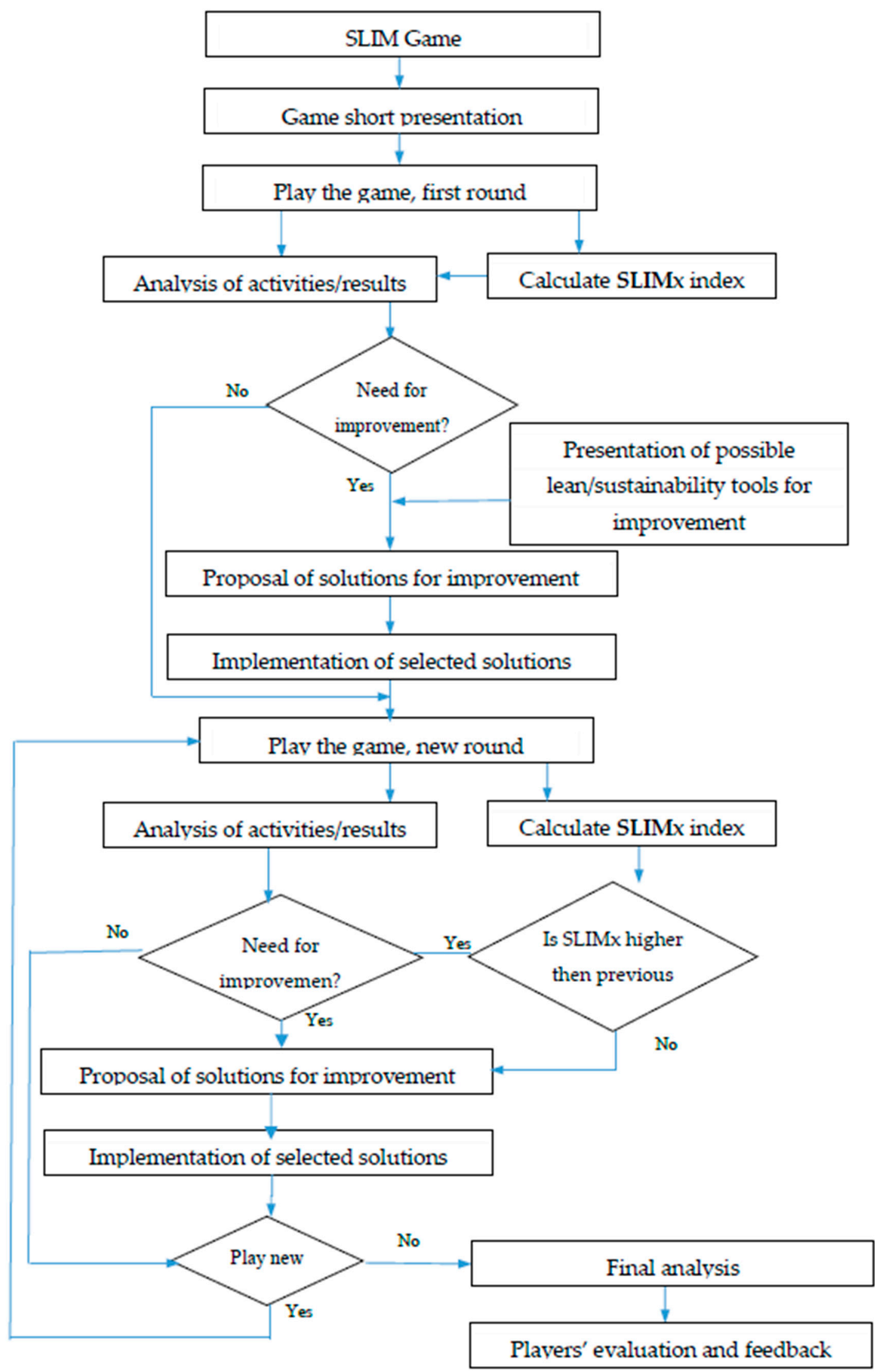

Figure 17. SLIM game algorithm. 
The solutions proposed by the players are discussed, approved (by the manager or by vote) and implemented. All procedures/forms needed to be modified are modified. Being a game, rewards/prizes can be considered and offered for different results obtained by the players during the game and at the end for individual and/or team success.

In the end, discussions may be moderated to find possibilities of implementing improvement proposals in enterprises, at the workplace of the players.

The game is flexible in different ways: duration, type and number of post/players, activities, ordering scenarios, etc. The game can run for a minimum recommendation of $60 \mathrm{~min}$, but it can take up to two, four, or more hours, depending on the duration of a round (recommended between 15 and $45 \mathrm{~min}$ ), depending on the number of players (minimum six, without a maximum), depending on the number of spare parts available, or depending on the customer order scenario (more or less products can be ordered, or less or more often during a round). Other types of posts can be added: logistics (transport between posts may be one of the most probable/frequent problems), human resources (player/employee evaluation), accounting and financial (to assess the results and establish the efficiency of the activity), and marketing (to promote products, establish new products, etc.).

We recommend to start the game without prior training of the players, all that they need to know and do is written in the job description. Additionally, the work instructions must be sufficiently detailed and clear that the activity can be performed, but with obvious (or less obvious) possibilities for improvement, such as: better activities description, more detailed information, clearer/larger pictures and step-by-step or piece-by-piece assembly algorithms. The game space should be sufficient, but also with the possibility to extend it if players propose, when bottlenecks appear on the activity flows.

The game was tested by playing it in a new educational laboratory with 15 players over three rounds, with teachers playing the supervisor position. The new educational laboratory, called "LeanSusLab" was created especially for teaching students using games, in the framework of a research project "Research and didactic laboratory: "Lean and Sustainability". The test results exceeded expectations. The players were happy, even delighted, by the game (general feedback score of 4.87 out of 5), as a role playing game (4.80) with the possibility to participate on actual processes of an enterprise, by individual and team work requirements, by the interactivity (4.93), and by the applicability of what they learn (4.60). Game shortcomings where more related to playing the game, as they do not understand exactly what and how they are supposed to do their job. A great deal of improvement possibilities and solutions were pointed out, and some of them were implemented with relative success (the trial and error method was emphasized). Following the game test in the laboratory, we validated the algorithm, activities, and forms of the game, and the SLIMx indicator was finalized as in Equation (1) previously presented (with subindicators in Equations (2)-(7)).

\section{Summary of Findings}

In this section are presented the most important directions identified during the development of the research:

- The profile of our respondents can be described as employees from companies operating in the automotive business sector $(50.70 \%)$, working in the administrative or support department $(43.08 \%)$ or technical department $(35.38 \%)$, and mostly having knowledge of both concepts (63.08\%).

- Individually asked about the concepts, we observed that respondents have a high knowledge about the concepts (73.85\% for "lean" and $89.23 \%$ for "sustainability" concepts).

- Correlating the results from Figure 5 with the profile of our respondents shows that most of them work in the administrative or support department (43.08\%) or technical department $(35.38 \%)$, and use specific tools for their working area: ISO Standards (75.38\%), 5S (64.62\%), and Problem Solving $(56.62 \%)$. 
- Correlating results from Figures 5 and 6 can conclude that the interviewed companies use and implement a vast palette of "lean" and "sustainability" tools.

- Correlating the results from Figures 7 and 8 we can conclude that the distribution of receiving and not receiving training for the "lean" and "sustainability" tools being almost equal has its justification in the fact that, for the type of training received, $44.62 \%$ did not receive training or we recorded missing values. This can be considered as an opportunity for our proposed game to be used by the interviewed companies.

- Although the companies' main pursued sustainability goals are decent work and economic growth $(69.23 \%)$, industry innovation and infrastructure (64.62\%), and responsible consumption and production $(61.54 \%)$, our interest also focuses on partnership for the goals $(60.00 \%)$ and quality education $(56.92 \%)$ because we consider all of them an opportunity for our proposed game to help companies in achieving the goals.

- The fact that a high majority of respondents consider "lean" and "sustainability" tools to be useful for the company's activity shows us the respondents' openness towards a better understanding of the concept and their tools.

- Correlating the findings presented in Figures 9 and 11 we can conclude that product quality and working conditions are of high interest for companies and its employees.

- Studying the top 10 overall company benefits based on respondents' perception presented in Figure 12, the main pursued sustainability goals presented in Figure 9, the usefulness of the tools presented in Figure 10 and are the top activities in which "lean" and "sustainability" tool implementation brought benefits presented in Figure 11, all come as a support to acknowledge the latent link between "lean" and "sustainability" concepts and their tools.

- The most important finding is that Waiting (46.16\%) and Defects or Scrap (40.00\%) are the highest frequency appearance drawbacks that respondents encounter in the company's activity. Additionally, these two types of drawbacks are the most common "lean" and "sustainability" tool's targets of improvement.

- It is noticed that $56.92 \%$ understand the importance of sustainability and report it. Even if there is no legislative requirement, $30.77 \%$ use standardized reporting, GRI. This strengthens the organizational concern for increasing competitiveness and improving public image.

- The team of the 15 people who played the SLIM game contributed to the generation of improvement solutions, including: streamlining the communication with the warehouse and with the managers, consolidating the position of the managers, the parts developed to be accompanied by additional instructions, and orders from customers to be verified by a leader.

- The team members were enthusiastically involved in the game. There was a general feedback score of 4.87 out of 5 ; as a role play (4.80), with the ability to participate in the real processes of an enterprise, through individual and team requirements, through interactivity (4.93), and through the applicability of what they learn (4.60).

\section{Conclusions, Discussion, and Limitations}

Possible application of the instrument/game are: students use the game for training in the mentioned domain (engineering and management) with the possibility to expand to other connected domain, at all levels (license, master, doctorate); the use of anyone who wants to perfect lifelong (post and pre-university level) learning; employees' use from the enterprises for professional perfection; and the use of potential employees and the unemployed for professional perfection/reconversion.

The use potential in the social and economic environments can be related to the possibility to exploit the intellectual property rights, especially for universities and other institutions and organizations/companies that offer training services.

The game has a limited number of job types, but with possibilities of extension already mentioned. Game applicability is limited to production processes, but with possibilities of extension to any 
workplace. It was designed as a paper-based system, which can be changed to a digitally-based system, using ITC technologies, mobile technologies-especially which can be used easily by players to check their role, responsibilities, work instructions, and forms to be filled in (digitally). These can help automated computation of results into KPIs, and the extension of KPIs used.

As future research the game should be used for education purposes in university and outside university, in companies interested in solutions for activity improvement. This supposes that the game should be tailored to meet specific needs anytime it is used. Before any use of the game, a needs study should be carried out, using the questionnaire already designed, but which can be modified according to research purposes.

The current research should be continued, and the questionnaire should be applied again in the future, at least yearly, with extension of the number of target companies/employees. The results can help improve the game to have a larger applicability in student education and in industry.

Author Contributions: All authors contributed equally to the research presented in this paper and to the preparation of the final manuscript.

Funding: This research was funded by Politehnica University of Timisoara, research grant PCD-TC-2017 number 15, contract number 16182/21.11.2017.

Acknowledgments: The authors want to acknowledge the support of Politehnica University of Timisoara, Faculty of Management in Production and Transportation, and Management Department for administrative and technical support, for the use of the infrastructure, especially for allowing to create a new laboratory for research and didactic use. We want to also acknowledge the implication of the authors' colleagues and students in the research and in designing and testing the new game. Additionally, we acknowledge the support of industry in the region for helpful discussions and survey responses.

Conflicts of Interest: The authors declare no conflict of interest.

\section{References}

1. Dües, C.M.; Tan, K.H.; Lim, M. Green as the new Lean: How to use Lean practices as a catalyst to greening your supply chain. J. Clean. Prod. 2013, 40, 93-100. [CrossRef]

2. Martínez-Jurado, P.J.; Moyano-Fuentes, J. Lean management, supply chain management and sustainability: A literature review. J. Clean. Prod. 2014, 85, 134-150. [CrossRef]

3. Piercy, N.; Rich, N. The relationship between lean operations and sustainable operations. Int. J. Oper. Prod. Manag. 2015, 35, 282-315. [CrossRef]

4. Adebanjo, D.; Laosirihongthong, T.; Samaranayake, P. Prioritizing lean supply chain management initiatives in healthcare service operations: A fuzzy AHP approach. Prod. Plan. Control 2016, 27, 953-966. [CrossRef]

5. Tasdemir, C.; Gazo, R. A Systematic Literature Review for Better Understanding of Lean Driven Sustainability. Sustainability 2018, 10, 2544. [CrossRef]

6. Govindan, K.; Azevedo, S.G.; Carvalho, H.; Cruz-Machado, V. Lean, Green and Resilient Practices Influence on Supply Chain Performance: Interpretive Structural Modeling Approach. Int. J. Environ. Sci. Technol. 2015, 12, 15-34. [CrossRef]

7. Egbue, O.; Wang, E.; Eseonu, C. A Lean Life Cycle Framework for Assessing Product Sustainability. In Proceedings of the IIE Annual Conference and Expo, Montréal, QC, Canada, 31 May-3 June 2014; pp. 2069-2074.

8. Cherrafi, A.; Elfezazi, S.; Govindan, K.; Garza-Reyes, J.A.; Benhida, K.; Mokhlis, A. A Framework for the Integration of Green and Lean Six Sigma for Superior Sustainability Performance. Int. J. Prod. Res. 2017, 55, 4481-4515. [CrossRef]

9. Ben Ruben, R.; Vinodh, S.; Asokan, P. Implementation of Lean Six Sigma Framework with Environmental Considerations in an Indian Automotive Component Manufacturing Firm: A Case Study. Prod. Plan. Control 2017, 28, 1193-1211. [CrossRef]

10. Das, D. Development and Validation of a Scale for Measuring Sustainable Supply Chain Management Practices and Performance. J. Clean. Prod. 2017, 164, 1344-1362. [CrossRef]

11. Camuffo, A.; de Stefano, F.; Paolino, C. Safety Reloaded: Lean Operations and High Involvement Work Practices for Sustainable Workplaces. J. Bus. Ethics 2015, 143, 245-259. [CrossRef] 
12. Shou, W.; Wang, J.; Wu, P.; Wang, X.; Chong, H.Y. A Cross-Sector Review on the Use of Value Stream Mapping. Int. J. Prod. Res. 2017, 55, 3906-3928. [CrossRef]

13. Vinodh, S.; Arvind, K.R.; Somanaathan, M. Tools and Techniques for Enabling Sustainability through Lean Initiatives. Clean Technol. Environ. Policy 2011, 13, 469-479. [CrossRef]

14. Faulkner, W.; Badurdeen, F. Sustainable Value Stream Mapping (Sus-VSM): Methodology to Visualize and Assess Manufacturing Sustainability Performance. J. Clean. Prod. 2014, 85, 8-18. [CrossRef]

15. Taucean, I.; Ivascu, L.; Miclea, S.; Negrut, M. Synergies between Lean and Sustainability: A Literature Review of Concepts and Tools. Qual. Access Success J. 2018, 20, 559-570.

16. Taucean, I.M.; Ivascu, L.; Negrut, M.; Miclea, S. Assessment of Lean Manufacturing and Sustainability Relationship in Production Processes. In Proceedings of the 32nd IBIMA Conference, Seville, Spain, 15-16 November 2018; pp. 255-262, ISBN 978-0-9998551-1-9.

17. European Commission. Europe 2020: Commission Proposes New Economic Strategy. Available online: https: / / ec.europa.eu/social/main.jsp?catId=89\&langId=en\&newsId=724\&furtherNews=yes (accessed on 30 December 2018).

18. Hugos, M. Enterprise Games: Using Game Mechanics to Build a Better Business, 1st ed.; O'Reilly Media: Newton, MA, USA, 2012.

19. Iftimescu, A. Business Games. Management of Simulated Enterprises. Available online: http://www.scribd. com/doc/121772636/Managementul-intreprinderilor (accessed on 1 October 2018).

20. Wells, R.A. Management Games and Simulations in Management Development: An Introduction. J. Manag. Dev. 1990, 9, 4-6. [CrossRef]

21. Tartavulea, R.I.; Belu, M.G.; Paraschiv, D.M. Using Business Simulation as a Complementary Educational Method in Universities. Ovidius Univ. Ann. 2012, XII, 138-142.

22. Taucean, I.M.; Matei, T. Research challenges for eLearning support in engineering and management training. Procedia-Soc. Behav. Sci. 2014, 124, 210-218. [CrossRef]

23. Ionita, F.; Cochina, I.; Shuleski, D. Never Stop Playing: Management Games as Valuable Training Tools. In Proceedings of the International Management Conference, Bucharest, Romania, 5-6 November 2015; Volume 9, pp. 266-277.

24. Condurache, G.; Daianu, D.C.; Taucean, I. Aspects regarding the competences of teacher/trainers in a practice enterprise. In Proceedings of the International Seminar on Quality Management in Higher Education Location, Quality Management in Higher Education, Iasi, Romania, 8-10 July 2006; pp. 55-59.

25. Pavaloiu, I.B. Games as student groundwork for business management training. In Proceedings of the International Conference, European Proceedings of Social and Behavioural Sciences, Pitesti, Romania, 4-5 November 2016; pp. 1016-1024. [CrossRef]

26. Trifan, L.; Mustata, C. Inducing entrepreneurial behaviour by business management simulation games. In Proceedings of the 7th International Conference on Education and New Learning Technologies (Edulearn15), Barcelona, Spain, 7-8 July 2015; pp. 6426-6433.

27. Ivascu, L.; Cioca, L.-I. Occupational Accidents Assessment by Field of Activity and Investigation Model for Prevention and Control. Safety 2019, 5, 12. [CrossRef]

28. Mocofan, M. Learning by games; a study case of the coffe project implementation in Romania. In Proceedings of the International Scientific Conference eLearning and Software for Education, Bucharest, Romania, 21-22 April 2016; Volume 1, p. 529.

29. Zamfir, A.; Plumb, I.; Dobrin, C.; Popa, I. Using computers and simulations in business education. In Proceedings of the 10th WSEAS international conference on Mathematics and computers in business and economics, Prague, Czech Republic, 23-25 March 2009; pp. 147-152.

30. Chichernea, V. Interactive methods used in graduate programs. Reliab. Qual. Control Pract. Exp. J. 2007, 2, 171-178.

(C) 2019 by the authors. Licensee MDPI, Basel, Switzerland. This article is an open access article distributed under the terms and conditions of the Creative Commons Attribution (CC BY) license (http:// creativecommons.org/licenses/by/4.0/). 